\title{
Implicit object naming in visual search: Evidence from phonological competition
}

\author{
Stephen C. Walenchok ${ }^{1} \cdot$ Michael C. Hout ${ }^{2} \cdot$ Stephen D. Goldinger ${ }^{1}$
}

Published online: 16 August 2016

(C) The Psychonomic Society, Inc. 2016

\begin{abstract}
During visual search, people are distracted by objects that visually resemble search targets; search is impaired when targets and distractors share overlapping features. In this study, we examined whether a nonvisual form of similarity, overlapping object names, can also affect search performance. In three experiments, people searched for images of real-world objects (e.g., a beetle) among items whose names either all shared the same phonological onset (/bi/), or were phonologically varied. Participants either searched for 1 or 3 potential targets per trial, with search targets designated either visually or verbally. We examined standard visual search (Experiments 1 and 3) and a self-paced serial search task wherein participants manually rejected each distractor (Experiment 2). We hypothesized that people would maintain visual templates when searching for single targets, but would rely more on object names when searching for multiple items and when targets were verbally cued. This reliance on target names would make performance susceptible to interference from similar-sounding distractors. Experiments 1 and 2 showed the predicted interference effect in conditions with high memory load and verbal cues. In Experiment 3, eye-movement results showed that phonological interference resulted from small increases in dwell time to all distractors. The results suggest that distractor names are implicitly activated during
\end{abstract}

Stephen C. Walenchok

swalench@asu.edu

Stephen D. Goldinger

goldinger@asu.edu

1 Department of Psychology, Arizona State University, P.O. Box 871104, Tempe, AZ 85287-1104, USA

2 New Mexico State University, Las Cruces, NM, USA search, slowing attention disengagement when targets and distractors share similar names.

Keywords Visual search · Phonological competitors · Eye movements $\cdot$ Multiple-target search

Imagine that you are cooking dinner and have set your ingredients and utensils on the counter, within easy reach. With a quick glance, it would be trivially easy to spot carrots on the counter among onions, potatoes, and garlic. Finding an onion, however, would likely require more careful discrimination: Background items create interference when they visually resemble search targets (Duncan \& Humphreys, 1989; Treisman \& Gelade, 1980; Wolfe, 2007; Wolfe, Cave, \& Franzel, 1989). In this study, we asked whether such interference might occur when targets and distractors share similar names, in the absence of visual similarity. For example, is searching for a beaker more difficult when the background items also have names with /bi/ onsets (e.g., beast, bean, and bee), relative to backgrounds with heterogeneous names? In three experiments, we investigated the conditions under which such phonological interference might occur.

Previous research has shown that nonvisual attributes of search items can influence the deployment of attention. For example, Moores, Laiti, and Chelazzi (2003) found that when distractor items were semantically related to targets, they attracted attention during visual search (see also Godwin, Hout, \& Menneer, 2014). In their experiment, participants were given verbal target cues before the brief presentation of search arrays. In post-search recall tests, participants better remembered distractors that were semantically related to target items (e.g., a lock if the target was a key) relative to unrelated distractors, and eye movements revealed more first fixations to target-related items, relative to unrelated items. 
Similarly, Huettig and Altmann (2005) found that semantic competitors can capture attention, using the visual world paradigm. Here, participants were instructed to freely view displays containing four items while listening to sentences containing a target word. People were more likely to fixate items related to the target word (such as a trumpet, given the target word piano), relative to unrelated distractors. Yee and Sedivy (2006) found that this semantic attention capture extends to distractors that are semantically related to phonological-onset competitors of the spoken target word. For instance, if the spoken target was log, participants tended to fixate a key because $\log$ phonologically overlaps with lock (see also Dahan \& Tanenhaus, 2005; Huettig \& Altmann, 2004; Yee, Overton, \& Thompson-Schill, 2009).

Several previous studies have also shown that phonological competition between targets and distractors can impair search efficiency in the absence of semantic competition. Using the visual world paradigm, Allopenna, Magnuson, and Tanenhaus (1998) presented participants with displays that contained distractors whose names partially overlapped with spoken targets, as either phonological onset or rhyme competitors (e.g., beetle or speaker, respectively, for the target word beaker). Eye-movement analyses showed that participants fixated onset and rhyme competitors in close alignment with phonological target segments as the spoken target unfolded in time (see also Huettig \& McQueen, 2007; Righi, Blumstein, Mertus, \& Worden, 2010). Meyer, Belke, Telling, and Humphreys (2007) obtained similar results with homophone competitors. Participants were initially familiarized with image names, then, in each experimental trial, were given visual target cues and made speeded target present-absent judgments to search displays. Search response times (RTs) were slower when homophone competitors were present (e.g., an image of the animal bat, given the search target baseball bat), and eyemovement data showed more frequent first fixations and longer fixations to homophone competitors relative to unrelated distractors. These results suggest that phonological competitors disrupt both visual guidance and decision-making processes - that is, distractor rejection. Görges, Oppermann, Jescheniak, and Schriefers (2013) found similar phonological competition effects in a paradigm identical to that from Meyer et al. (2007), except that participants were presented with either visual or verbal target cues before search. Although target detection was faster overall with visual cues, the degrees of phonological interference were equivalent in both conditions. Furthermore, this verbal interference only occurred when participants were familiarized with the names of the stimuli before the experiment, suggesting that people use both visual and verbal target information to varying degrees when searching, depending on the salience of these object properties. Taken together, these results suggest that participants may implicitly activate phonological dimensions of visual stimuli, at least under certain conditions.
Regarding the conditions that encourage such phonological activation, research has suggested that implicit object naming may increase as a function of memory demands. Zelinsky and Murphy (2000) presented participants with two different tasks, a recognition task with high memory demand, and a visual search task with low memory demand. In the recognition task, participants were initially shown multiple common objects or faces whose names contained one or several syllables. Afterward, they had to judge whether singularly presented objects were old or new. Analyses of eye-movements during encoding revealed more fixations and longer gaze durations on objects whose names contained multiple syllables, compared to single-syllable items. A subsequent analysis showed a high correlation between the time required to vocalize object names and gaze duration on those objects, suggesting that participants were implicitly naming stimuli during encoding. No effect of syllable length was found in visual search, which had comparatively smaller encoding requirements (i.e., searching for a single target).

In this study, we examined two factors that we considered likely to modulate degrees of phonological coding of search targets. First, we manipulated the number of potential targets per trial, increasing memory demand for multiple-target search (Hout \& Goldinger, 2010, 2012, 2015; Zelinsky \& Murphy, 2000). Second, we presented search targets either as images or as verbal labels. By manipulating both of these factors in three experiments, we examined whether the combination of memory demands (e.g., Zelinsky \& Murphy, 2000) and verbal labels (e.g., Görges et al., 2013) encouraged implicit naming of search targets and thereby elicited phonological interference from background, distractor items. In contrast to previous visual search studies that have examined phonological competition with simple four-item displays (e.g., Görges et al., 2013; Meyer et al., 2007), we tested using a more traditional search task (in Experiments 1 and 3), with many items scattered in unpredictable positions around the display. This paradigm enabled us to further examine whether phonological competitors inhibit object identification and visual guidance processes when people perform challenging visual search.

Across experiments, participants were cued to search for either one or three potential target objects per trial, one of which could appear among distractor objects in a subsequent search array. In the critical condition, target and distractor objects' names shared a phonological onset (e.g., beaker, beast, and beanie). This was compared to several control conditions (as described below). We also varied whether participants were cued using target images or names, anticipating that name cues would reduce immediate visual matching and would make target-object names more active in working memory (WM). Without having exact target representations in visual WM, we expected participants to process distractors to a greater degree, in order to reject them. Such prolonged 
processing would theoretically allow more time for object names to become activated, potentially creating phonological interference. However, the memory requirements of singletarget search are low, relative to simultaneously searching for three potential targets. With only one target in mind, people may generate visual representations from verbal cues, using them as templates to guide search (Schmidt \& Zelinsky, 2009), thereby minimizing potential phonological interference. Taking these manipulations together, we expected evidence for phonological competition to mainly emerge in the condition combining verbal cues and multiple-target search.

Experiment 1 involved standard visual search, with participants searching spatial arrays of objects for targets, confirming their presence or absence. Along the way, viewed distractors must be rejected as nontargets. Although search RTs provide a fairly coarse measure of distractor rejection time, they can indicate whether global differences arise from phonological competition. To more precisely examine distractor rejection, Experiment 2 presented each search item serially (self-paced RSVP), requiring a series of overt distractor rejections per trial. In Experiment 3, we again used standard visual search and recorded eye movements to better assess distractor processing without requiring overt decisions to each.

\section{Experiment 1}

We examined phonological competition effects in a standard visual search task. Participants searched for one (low load) or three (high load) targets among pseudorandomly distributed distractor objects. Participants were cued with target images in Experiment 1a and target names in Experiment 1b.

\section{Method}

\section{Participants}

Twenty and 22 undergraduate students from Arizona State University participated in Experiments $1 \mathrm{a}$ and $1 \mathrm{~b}$, respectively, for partial course credit. All participants were native English speakers and self-reported normal or corrected-tonormal vision. All procedures were approved by the Arizona State University Institutional Review Board.

\section{Design}

All variables in each experiment were manipulated within-subjects, including Target Presence (present or absent), Set Size (12, 16, or 20 objects per search display), Load (one or three potential targets), and Competition (phonological competition or control). In all experiments, the variable Competition included four levels. First was the critical phonological competition condition, wherein potential targets and all distractors shared an initial /bi/ consonant-vowel (CV) onset in a trial (see Table 1). We also included three separate control conditions, with targets and distractors combined in all possible ways: (1) /bi/ targets with varied distractors, (2) varied targets with /bi/ distractors, and (3) varied targets and distractors. Each participant was presented with an equal number of trials within each combination of conditions. For example, there were four trials total in which a target was present at Set Size 12 with a single potential target among a background of phonological competitors. We included all three control conditions to ensure that any effects truly reflected competition between targets and distractors in the critical condition rather than idiosyncratic properties of any particular items. Across experiments, the control conditions produced nearly identical results, often appearing as overlapping lines when plotted. Separate ANOVAs were conducted for only the control conditions: In the few instances wherein results in these conditions reliably differed, they produced no systematic pattern across experiments (full results from each control condition in all experiments

Table 1 Stimuli for all experiments

\begin{tabular}{ll}
\hline Phonological Competitors & Noncompetitors \\
\hline beach ball & chain \\
beacon & chainsaw \\
beads & funnel \\
beagle & glasses \\
beak & hammer \\
beaker & harmonica \\
beam & joystick \\
bean & keyboard \\
beanbag & lighter \\
beanie & monkey \\
beanstalk & pepper \\
beard & popsicle \\
beast & pretzel \\
beater & ring \\
beaver & robot \\
bee & shark \\
beef & skull \\
beehive & snail \\
beekeeper & stamp \\
beeper & stapler \\
beer & table \\
beetle & turtle \\
beets & witch \\
\hline &
\end{tabular}


are provided in Appendix B). For clarity, we collapsed across the separate control conditions for the main analyses; this averaging had no impact on the reported results. The key dependent variable was search RT in correct trials.

\section{Stimuli}

The stimuli were images of real-world objects, converted to grayscale and resized to $2.9^{\circ} \times 2.9^{\circ}$ visual angle (centered) from a viewing distance of $60 \mathrm{~cm}$. Stimuli were sampled from a list of 23 phonological competitors and 23 control items (see Table 1). The list of phonological competitors contained items whose names shared a /bi/ CV onset (e.g., beaker, beast, beanie) whereas the control list contained items with varied onsets (e.g., snail, pretzel, turtle). Target and distractor items were randomly sampled from these lists per trial, appropriate to the competition or control condition for that given trial.

\section{Apparatus}

All data were collected on up to 12 computers simultaneously, with identical hardware and software profiles, consisting of Dell Optiplex 380 PCs at $3.06 \mathrm{GHz}$ and 3.21 GB RAM, in $1366 \times 768$ resolution on Dell E1912H 18.5-in. monitors at a $60 \mathrm{~Hz}$ refresh rate, with the display controlled by an Intel G41 Express chipset, each running on Windows XP. All stimuli were presented using E-Prime 1.2 software (Schneider, Eschman, \& Zuccolotto, 2002).

\section{Procedure}

Before the visual search task, participants were familiarized with the names of all stimuli to reduce name ambiguity. During the familiarization task, one item was centrally presented per trial, along with one plausible name and one foil (i.e., a concrete noun unrelated to the object). Participants chose the correct name for each object by pressing $f$ or $j$ on the keyboard. The locations of the plausible and foil names were randomized, and participants received accuracy feedback in every trial. A minimum accuracy of $85 \%$ was required to proceed to the main experiment; no participants fell below this criterion.

The search task included eight practice trials and 192 experimental trials, with a 2-minute break midway through the experiment. Figure 1 shows a schematic progression of trial events. In each trial, participants were cued with the possible target(s), followed by a $500-\mathrm{ms}$ fixation cross, and then the search display. A search array algorithm was used to create displays with pseudorandom organization (Hout \& Goldinger, 2010, 2012, 2015): Each display quadrant was divided into nine equal-sized (but invisible) cells. Within each quadrant, objects were randomly placed within these cells, with the constraint that equal numbers of objects occupied each quadrant. Each object's location was then randomly jittered within each cell, giving the appearance of truly random organization. Participants were instructed to determine target presence or absence as quickly and as accurately as possible, terminating search by pressing the space bar. They were then shown a subsequent screen in which they confirmed target presence or absence by pressing the $f$ or $j$ keys, respectively, and were given accuracy feedback. Correct feedback consisted of a green check mark presented for $1,000 \mathrm{~ms}$, and incorrect feedback consisted of a red $X$ presented for 2,000 ms. In low-load trials, a single target was initially presented, whereas in highload trials, three potential targets were initially presented (only one could appear in the search display, and instructions made participants aware of this.) Low- and high-load trials were randomly intermixed. Image target cues were used in Experiment 1a, and name cues were used in Experiment $1 \mathrm{~b}$ (see Fig. 2).

\section{Results}

Average search accuracy in Experiment 1a was $93 \%$. Three participants were excluded from analysis in Experiment 1b, two because of technical malfunctions and one because of missing data (i.e., no correct trials in one condition). Average accuracy for the remaining 19 participants in Experiment $1 \mathrm{~b}$ was $90 \%$. All data were analyzed using repeated-measures ANOVAS and twotailed $t$-tests for pairwise comparisons. Where applicable, multivariate tests are reported to account for violations of the sphericity assumption (Keppel \& Wickens, 2004). Several analyses were conducted per experiment, first including all variables, then separately examining targetabsent and target-present trials. Given that people are roughly twice as fast to terminate search in targetpresent trials (Treisman \& Gelade, 1980), target-absent trials allow for greater inspection of distractor items, and distractor interference in these trials was our primary interest (see also Görges et al., 2013; Moores et al., 2003).

\section{Experiment 1a: Image cues}

The results for Experiment 1a are shown in the upper panels of Fig. 3. For clarity, the ANOVA results are provided in Appendix A (see Table A1), and we focus on key findings in the main text. In the full analysis, there were main effects of Load, Target Presence, and Set Size, all in their typical directions: Participants were slower when searching for multiple targets, and when set sizes were larger, and when targets were absent. (Because these basic findings are well-established in visual search, we mention them only briefly in all remaining analyses.) We also observed a main effect of Competition, shown in Fig. 3 by slightly separated lines, with slower 


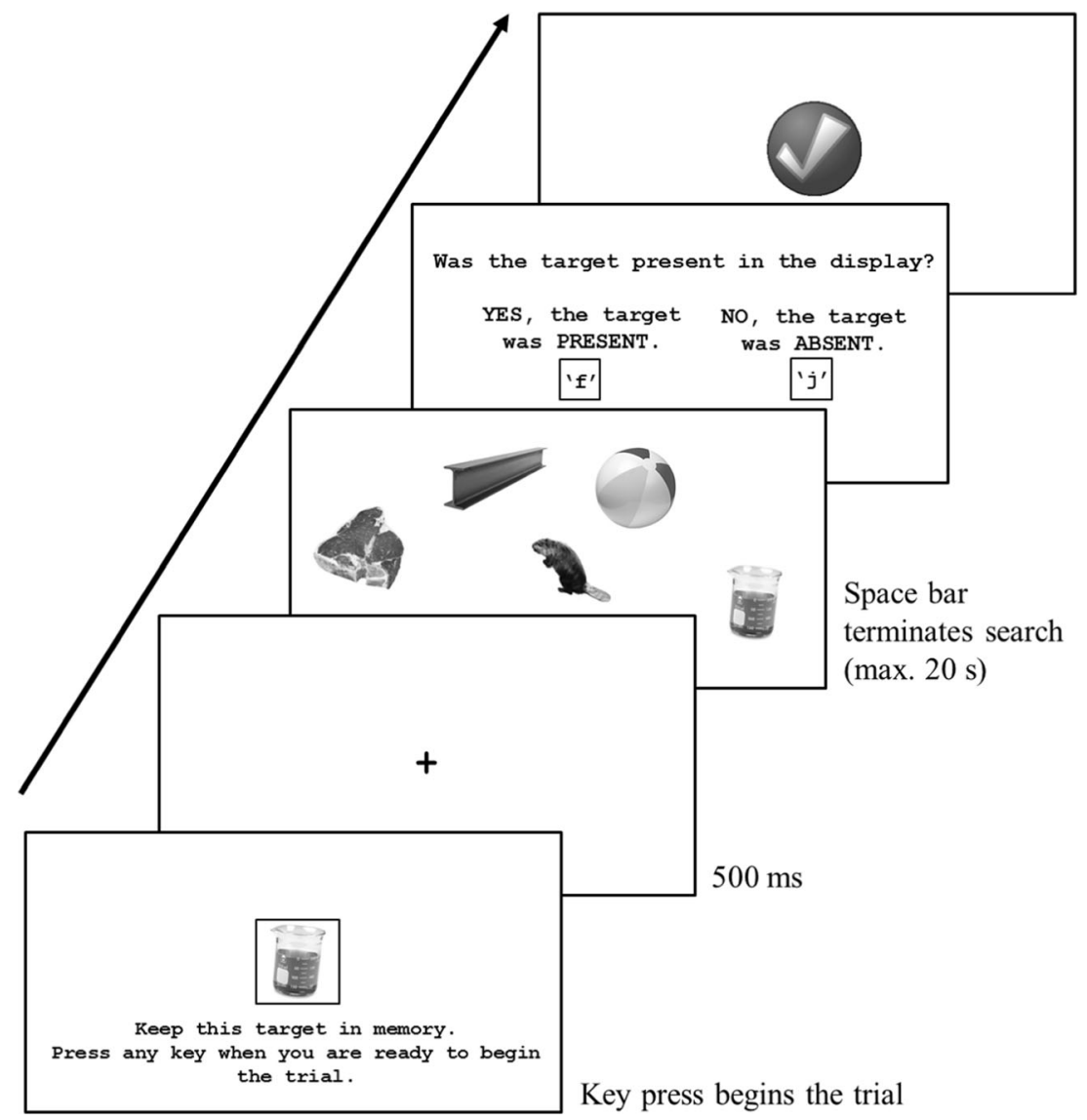

Fig. 1 Progression of trial events in Experiment 1. Note that the search set size was 12, 16, or 20 items; fewer objects are depicted in the figure for clarity

responses in competition trials, relative to control. The finding of key interest was the Load $\times$ Competition interaction: In low-load trials, no competition effect was observed (with mean RTs of $1,865 \mathrm{~ms}$ and $1,865 \mathrm{~ms}$ in control and competition trials, respectively), $t(19)<0.01, p=.999$. But, in highload trials, mean RTs were faster in control trials $(3,615 \mathrm{~ms})$, relative to competition trials $(3,898 \mathrm{~ms}), t(19)=2.98, p=.008$, $d=.67$.

Again, because our main interest concerned distractor rejection, we separately examined target-present and targetabsent trials, anticipating stronger effects in target-absent trials (because they entail exhaustive search). In target-present trials, there were again main effects of Load, Competition, and Set Size. As the upper right panel of Fig. 3 shows, search RTs were slower in competition trials than control trials $(1,956 \mathrm{~ms}$ and $1,786 \mathrm{~ms}$, respectively). There was a marginal Load $\times$ Competition interaction $(p=.077)$ in the same direction as in the overall ANOVA. In the target-absent trials, there were again main effects of Load, Competition, and Set Size. The Competition effect reflected slower RTs in competition trials $(3,806 \mathrm{~ms})$, relative to control trials $(3,694 \mathrm{~ms})$. The key Load $\times$ Competition interaction was again marginal $(p=.067)$. Taking these results together, Experiment 1a provided weak evidence for the predicted result, as competition effects emerged when participants performed multiple-target search. We expected these effects to be stronger in Experiment 1b, which involved verbal target cues.

\section{Experiment 1b: Verbal cues}

The results for Experiment $1 \mathrm{~b}$ are shown in the lower panels of Fig. 3 and in Appendix A (Table A2). In the full analysis, there were main effects of Load, Target Presence, and Set Size, again, all in their typical directions. We also observed a main effect of Competition, with slower RTs in competition trials relative to control trials. The finding of key interest was the Load $x$ Competition interaction: In low-load trials, no competition effect was observed (with mean RTs of 2,256 ms and $2,257 \mathrm{~ms}$ in control and competition trials, respectively), $t(18)=0.02, p=.988$. But in high-load trials, mean RTs were faster in control trials $(4,282 \mathrm{~ms})$ relative to competition trials $(4,787 \mathrm{~ms}), t(18)=4.37, p<.001, d=1.00$. There were two key interactions. The Load $\times$ Competition interaction verified that RTs were slowest in multiple-target, competition trials. The Load $\times$ Competition $\times$ Target Presence interaction suggests that this Load $\times$ Competition interaction mainly emerged in target-absent trials. 
Target Cue:

Distractors:

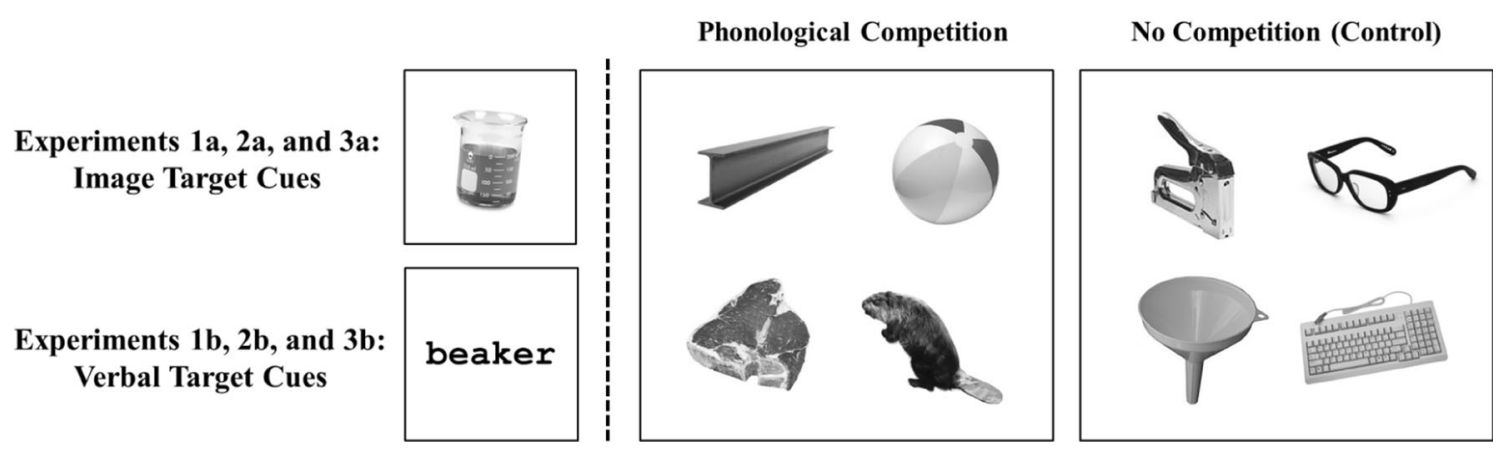

Fig. 2 Conditions in Experiments 1-3. Note that the set size was more than four; it is reduced here for demonstration

In the target-present trials, there were main effects of Load and Set Size, and a marginal effect of Competition. The critical Load $\times$ Competition interaction was not reliable (see lower right panel of Fig. 3). In the target-absent trials, there were main effects of Load, Set Size, and Competition. The key Load $\times$ Competition interaction showed that during

\section{Experiment 1a: Image Target Cues}

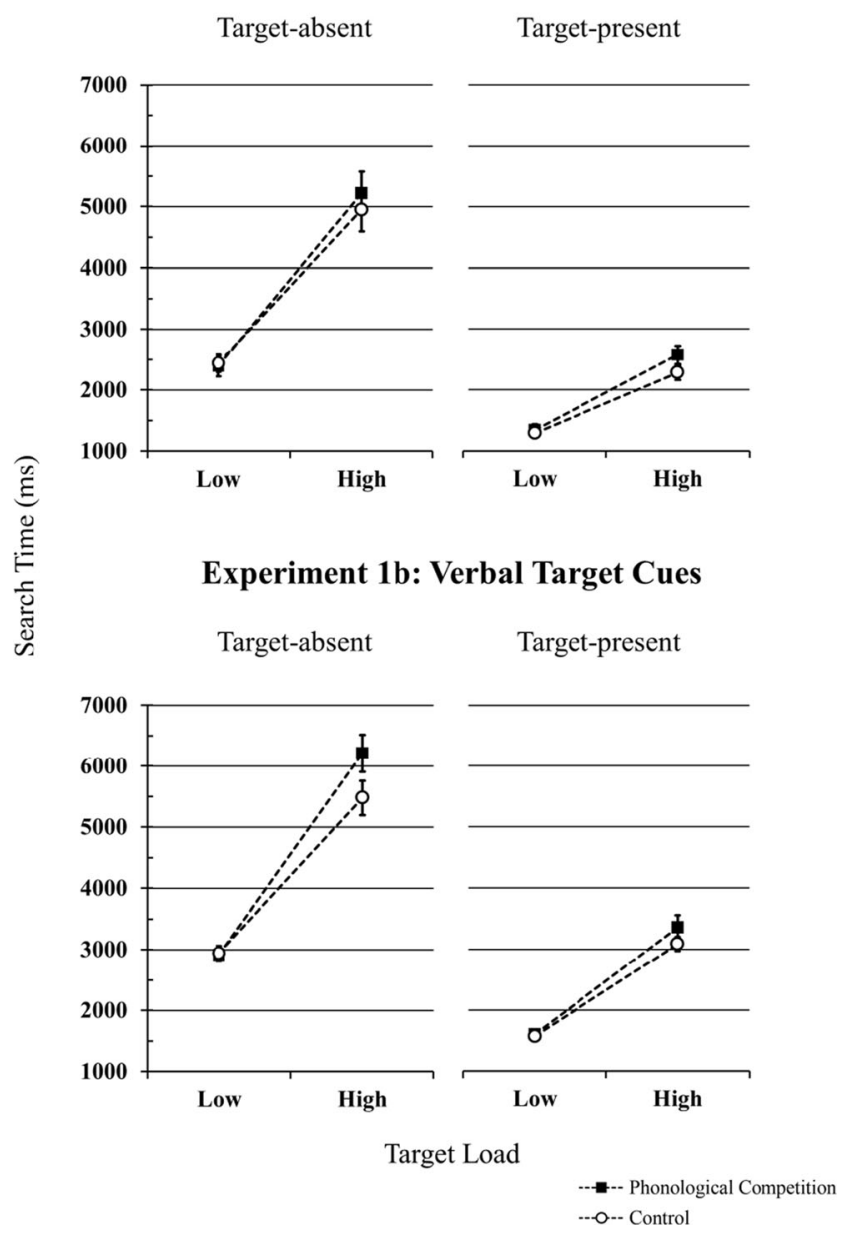

Fig. 3 Search time (RT) as a function of Competition, Load, and Target Presence, in Experiments 1a and 1b. Error bars represent \pm 1 SEM multiple-target search, RTs were slowed by phonological competitors. Under low target load, mean RTs to control and competition trials were $2,942 \mathrm{~ms}$ and $2,916 \mathrm{~ms}$, respectively, $t(18)=0.39, p=.701$. Under high load, these values diverged, with mean RTs of $5,479 \mathrm{~ms}$ and $6,214 \mathrm{~ms}, t(18)=$ $6.04, p<.001, d=1.39$ (see lower left panel of Fig. 3). The overall pattern in Fig. 3 suggests stronger competition effects in Experiment $1 \mathrm{~b}$ relative to Experiment 1a. This was tested in a combined ANOVA, conducted specifically to assess the potential Experiment $\times$ Load $\times$ Competition interaction, but this was not reliable, $F(1,37)=1.44, p=.238$, nor was the Experiment $\times$ Competition interaction, $F(1,37)$ $=2.39, p=.131$.

\section{Discussion}

In Experiment 1, participants searched for objects, either in trials wherein target and distractor names were heterogeneous or in trials wherein all depicted objects shared the phonological onset /bi/. When people searched for singular targets, RTs were unaffected by phonological similarity among the target and distractors. However, when searching for multiple potential targets, people were slower in competition trials relative to control trials. This pattern was especially evident when targets were specified verbally rather than visually. Note, however, that distractor object names were never task relevant. Instead, they appeared to be activated automatically, impacting search when processing demands were high.

The lack of phonological competition observed when processing demands were low (i.e., in single-target search) stands in contrast to Meyer et al. (2007) and Görges et al. (2013), who found phonological competition effects when people searched for single items. Task differences offer one potential explanation for the discrepant findings: Meyer et al. (2007) and Görges et al. (2013) presented smaller displays with four items in predictable locations, whereas our displays contained 12,16 , or 20 randomly distributed items. Indeed, the greater complexity of the current task was evident in slower overall 
search RTs (e.g., 1,865 ms in Experiment 1a in single-target search compared to $645 \mathrm{~ms}$ in the comparable condition of Görges et al., 2013, and $800 \mathrm{~ms}$ in Meyer et al., 2007). The greater complexity in our displays could have limited the attention that participants devoted to individual items, reducing phonological activation and therefore interference in singletarget search. We examine this point further with eye tracking in Experiment 3.

The discrepant findings may also reflect differences between respective stimulus sets. Our phonological competitors included items that shared only phonological onsets, whereas Meyer et al. (2007) and Görges et al. (2013) used homophone and rhyme competitors, respectively, that shared greater phonological similarity to one another. Our stimuli only shared a /bi/ onset, whereas those from previous studies shared salient rhymes as well. The greater phonological overlap between target and competitor names in these prior experiments likely elicited greater interference in single-target search that we failed to observe with weaker phonological competitors (Grosjean, 1980; Tyler, 1984).

Although phonological competition largely did not emerge in single-target search in Experiment 1, this interference was strong when people searched for multiple targets. What might explain the Experiment 1 results? To offer a potential account, we must adopt two relatively straightforward assumptions and one novel hypothesis. First, we assume that when a person views an image of some object (e.g., a dog), the experience is not entirely visual. Instead, the object name also becomes partially active in memory, along with associated knowledge (e.g., Huettig \& Altmann, 2005; Yee \& Sedivy, 2006). These implicit dimensions may not reach a level of conscious awareness, but we assume they receive some degree of activation. Second, we assume that multiple-target search, combined with verbal target cues, encourages verbal coding to maintain target identities during search (Baddeley \& Hitch, 1974). With these assumptions in place, we hypothesize that visual search involves "resonance seeking" between targets in WM and objects in the search array. When target representations are mainly visual, attention will mainly be drawn to visually viable candidates. But, when verbal labels are more prominent in WM, attention will also be drawn to phonologically viable candidates.

Even in this simple framework, the competition effect in Experiment 1 might reveal disruption of attentional guidance, perceptual matching, or both. With respect to guidance, Menneer et al. (2012) found that visual guidance is hindered in multiple-target search (see Hout \& Goldinger, 2015, for similar findings). When searching for multiple potential targets, people both fixate more target-dissimilar items and fewer target-similar items, relative to searching for singular targets. People are also more likely to revisit previously inspected objects during multiple-target search. Therefore, when searching under high WM load, the capacity to effectively guide attention is reduced. In Experiment 1, this reduced attentional guidance would suggest that people considered more distractors in the highload condition, relative to the low-load condition. When more distractors are viewed, it may increase the likelihood of individual object names becoming active and causing interference when they overlap with the targets held in memory. Consequently, this interference might generally inhibit the effective deployment of attention, resulting in more fixations to nontargets when phonological competitors are present. Alternatively (or additionally), given greater phonological resonance between targets in WM and fixated objects, it may take more processing for people to reject distractor objects and disengage attention. In Experiment 1, this mechanism would suggest that fixated items would hold attention longer and perhaps that target identification would be slower. To simplify interpretation, we removed the need for attentional guidance in Experiment 2.

\section{Experiment 2}

In Experiment 2, we used the same stimuli as in Experiment 1 (arranged in the same critical and control conditions). The task was changed, however, to a self-paced serial search procedure that required participants to verify whether each viewed object was a target or a distractor. Each trial consisted of a stream of distractors, with targets embedded in $75 \%$ of trials, as explained below. As before, Experiment 2 a presented visual target cues, and Experiment $2 \mathrm{~b}$ presented verbal target cues.

\section{Method}

\section{Participants}

Experiments $2 \mathrm{a}$ and $2 \mathrm{~b}$ included 23 and 22 Arizona State University students, respectively, with the same inclusion criteria as were applied in Experiment 1.

\section{Stimuli and design}

All variables from Experiment 1 were included in Experiment 2, although "set size" now referred to the number of items serially presented $(12,16$, or 20$)$. Rather than search RT, the key dependent variable was mean distractor rejection times from correct trials. The stimuli and apparatus were identical to those used in Experiment 1.

\section{Procedure}

Participants initially performed the stimulus familiarization task, as in Experiment 1. For the serial search task, 
the procedure was analogous to Experiment 1 (see Fig. 4). Each participant was initially instructed to search for one or three potential targets and was then shown a series of centrally located objects, with self-paced presentation. Participants were instructed to reject each successive distractor by pressing the space bar, or to verify target detection by pressing the enter key. Each item was masked with a patch of visual noise for $50 \mathrm{~ms}$ after each response, followed by a 50 -ms blank screen before the onset of the next item in the stream. Each trial terminated when the enter key was pressed or once all items were exhausted. When a target was present, its location in the search stream was randomized.

Target-present trials were considered valid for RT analyses only if the participant correctly detected the target (i.e., a hit). In every trial wherein participants reached the end of the stream without pressing enter, they were prompted to indicate whether they had seen a target. In this manner, participants could correct for simple motor errors (see Fleck \& Mitroff, 2007), although target-present trials with late target detection were considered incorrect in the analyses. Target-absent trials were scored as correct only if the participant rejected all distractors and subsequently verified that no target was present. Depending upon circumstances, participants were given different feedback at the end of a trial. For correct rejections and hits, they received "correct" feedback for $500 \mathrm{~ms}$ (see Fig. 4). If they pressed the enter key incorrectly, the message "False alarm!" was shown for 2,000 ms. If they failed to detect a target, the message "You missed!" was shown for 2,000 ms. The message "Remember to press ENTER when you see a target!" was shown for late, correct target verification, and "There was actually no target present" was shown for late false alarms, each also for 2,000 ms.

Although Experiment 1 used a 50/50 division of targetpresent and target-absent trials, a pilot experiment revealed low hit rates in the self-paced serial-presentation task. This appeared to reflect the disengagement of attention when so many items required the space-bar response. To improve performance, we increased target prevalence from $50 \%$ to $75 \%$, with targets present in 144 out of 192 trials. Participants completed eight initial practice trials in each experiment.

\section{Results}

When we examined the full design (including the variables Load, Competition, Target Presence, and Set Size), seven participants had missing data, with no correct trials in at least one condition. Preliminary ANOVAs were conducted, excluding

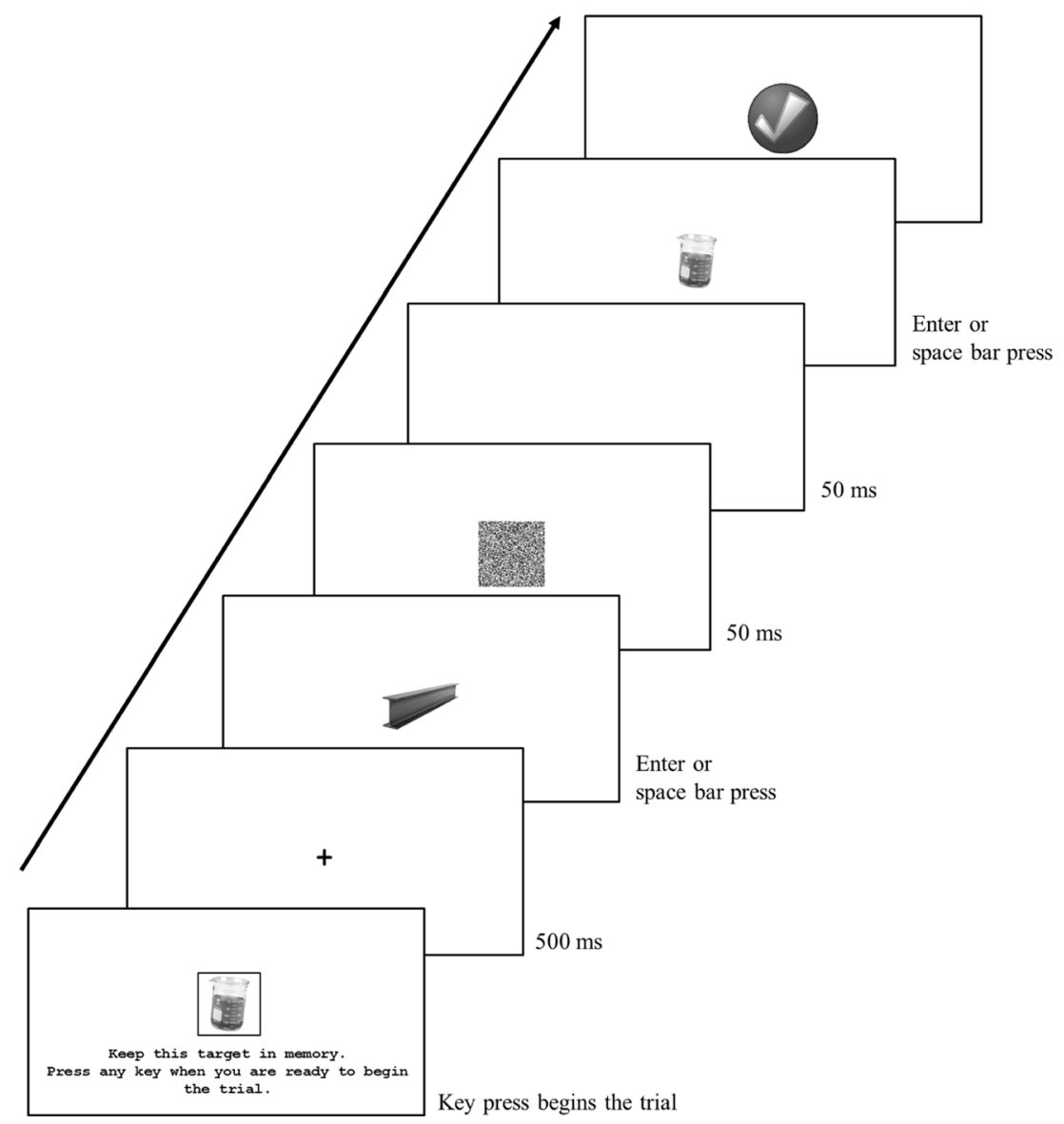

Fig. 4 Trial progression in Experiment 2 
these participants, showing that Set Size did not interact with the critical Competition variable. We therefore collapsed across values of Set Size, which yielded enough correct trials to retain these participants. The final analyses therefore included the variables Load (low, high), Competition (competition, control), and Target Presence (absent, present). One participant was excluded from analysis in Experiment 2 a due to slow distractor rejection times ( $>2.5$ SDs above the mean). Average accuracy for the remaining 22 participants was $79 \%$. Two participants were excluded from analysis in Experiment $2 \mathrm{~b}$ - one for falling asleep during the task and one for having slow distractor rejection times $(>2.5 S D$ s above the mean). Accuracy for the remaining 20 participants was $83 \%$. Because our dependent measure was average distractor rejection time, an additional $4 \%$ of trials were excluded from analysis in both experiments because targets occurred as the first item in the search stream.

\section{Experiment 2a: Image cues}

The results from Experiment $2 \mathrm{a}$ are shown in the upper panels of Fig. 5, with target-absent trials on the left and target-present trials on the right, and in Appendix A (Table A3). As shown, the general RT pattern resembled that from Experiment 1, with small competition effects that emerged in high-load conditions. In the full ANOVA, there were main effects of Load, Competition, and Target Presence. The latter effect occurred because average distractor rejection times were slightly faster in target-absent trials (495 ms) than target-present trials $(516 \mathrm{~ms})$. The critical Load $\times$ Competition interaction was reliable. As the diverging lines in Fig. 5 indicate, distractor rejection times were faster in control trials $(580 \mathrm{~ms})$ than in competition trials $(620 \mathrm{~ms})$ when participants searched under high target load, $t(21)=3.75, p=.001, d=.80$, but not under low load (410 and $411 \mathrm{~ms}$ in control and competition trials, respectively), $t(21)=0.29, p=.773$.

In target-present trials (Fig. 5, upper right panel), there were main effects of Load and Competition, and another Load $\times$ Competition interaction. In the low-load condition, mean distractor rejection times in the control and competition trials were $414 \mathrm{~ms}$ and $416 \mathrm{~ms}$, respectively, $t(21)=0.12, p=.903$. In the high-load condition, these values diverged, with mean RTs of $593 \mathrm{~ms}$ and $642 \mathrm{~ms}$, $t(21)=3.71, p=.001, d=.79$. In the target-absent trials (Fig. 5, upper left panel), there were again main effects of Load and Competition, with overall faster distractor rejection in control trials $(487 \mathrm{~ms})$ than in competition trials $(503 \mathrm{~ms})$. The Load $\times$ Competition interaction was marginal, with a numerical trend in the same direction as was observed in target-present trials. As in Experiment 1, although trials with visual target cues showed phonological competition effects under high WM load, these effects were fairly small.

Experiment 2a: Image Target Cues

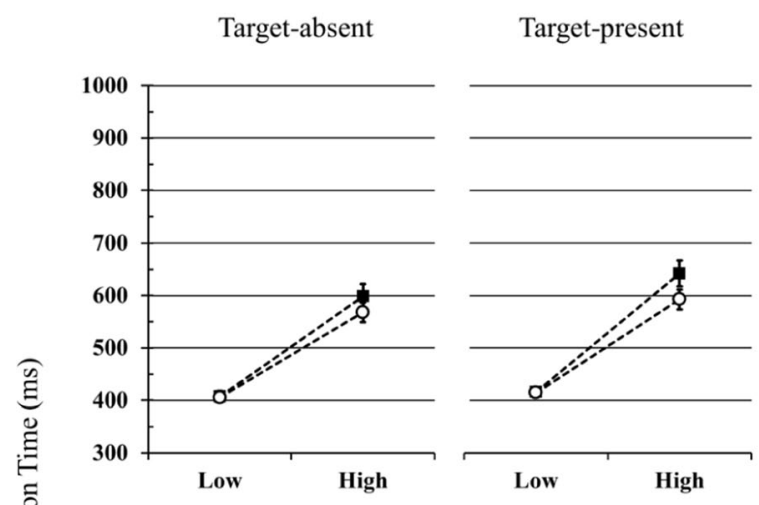

Experiment 2b: Verbal Target Cues

Target-absent

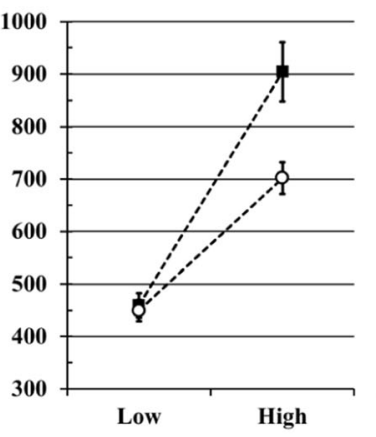

Target Load
Target-present

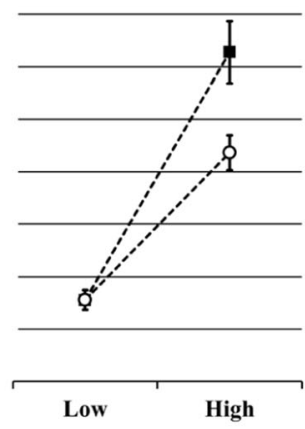

-.- Phonological Competition -..-.- Control

Fig. 5 Mean distractor rejection time, as a function of Competition, Load, and Target Presence, in Experiments 2a and 2b. Error bars represent $\pm 1 S E M$

\section{Experiment 2b: Verbal cues}

The results from Experiment $2 \mathrm{~b}$ are shown in the lower panels of Fig. 5, with target-absent trials on the left and target-present trials on the right, and in Appendix A (Table A4). As shown, the competition effects under high-load were far stronger, relative to Experiment 2a. In the full ANOVA, there were main effects of Load and Competition, but Target Presence was not significant. The critical Load $\times$ Competition interaction was significant, as indicated by the diverging lines in the lower panels of Fig. 5. In the low-load condition, mean distractor rejection times in control and competition trials were $453 \mathrm{~ms}$ and $457 \mathrm{~ms}$, respectively, $t(19)=0.64, p=.528$. In the highload condition, these values diverged, with mean rejection times of $719 \mathrm{~ms}$ and $916 \mathrm{~ms}$, respectively, $t(19)=6.94, p<$ $.001, d=1.55$.

In the target-present trials (Fig. 5, lower right panel), there were main effects of Load and Competition, and a Load $\times$ Competition interaction. With respect to the interaction, in 
the low-load condition, mean distractor rejection times in control and competition trials were $456 \mathrm{~ms}$ and $456 \mathrm{~ms}$, respectively, $t(19)=0.05, p=.962$. In the high-load condition, these values increased and diverged, with means of 736 and $927 \mathrm{~ms}$, $t(19)=5.26, p<.001, d=1.18$. In the target-absent trials (Fig. 5, lower left panel), there were again main effects of Load and Competition. The Load $\times$ Competition interaction was again significant, with strong competition effects emerging under high load. In the low-load condition, mean distractor rejection times in control and competition trials were $449 \mathrm{~ms}$ and $459 \mathrm{~ms}$, respectively, $t(19)=1.04, p=.311$. In the highload condition, these values again increased and diverged, with means of $702 \mathrm{~ms}$ and $904 \mathrm{~ms}, t(19)=6.06, p<.001, d$ $=1.36$. Again, the overall pattern of Fig. 5 suggests stronger competition effects in Experiment $2 b$ relative to Experiment 2a. This was tested in a combined ANOVA, conducted specifically to assess the potential Experiment $\times$ Load $\times$ Competition interaction, which was reliable, $F(1,40)=$ 26.82, $p<.001, \eta_{\mathrm{p}}^{2}=.40$, as was the Experiment $\times$ Competition interaction, $F(1,40)=25.73, p<.001, \eta_{\mathrm{p}}^{2}=.39$.

\section{Discussion}

In Experiment 2, we administered a serial search task in which participants had to manually reject distractors and confirm targets in streams of centrally presented items. This procedure allowed us to assess distractor rejection processes, independent from the guidance of attention. Despite the different procedure, the results were similar to those observed in Experiment 1: When looking for multiple targets, participants were slower to reject distractors that shared a phonological onset with the potential targets held in memory. This phonological interference was again stronger when participants were given verbal target cues. Overall, this pattern suggests that distractor rejection is detrimentally affected by phonological competition. More specifically, it suggests that when distractor objects have similar names to target objects, it takes people slightly longer to reject those distractors, even though object names are irrelevant to the task. To simultaneously assess both attention guidance and distractor rejection, we next conducted a replication of Experiment 1 while recording participants' eye movements.

\section{Experiment 3}

Our results thus far have shown clear effects of phonological competition, evidenced by slower overall search (Experiment 1) and slower distractor rejection (Experiment 2) in the presence of phonological competitors. Although Experiment 2 showed that target-distractor name similarity interfered with the distractor rejection, several questions remain about generalizing this interference to standard visual search. For instance, we have yet to show whether such distractor rejection, attentional guidance, or a combination of both processes are hindered by phonological similarity. In Experiment 3, we returned to the standard search paradigm, coupled with eyetracking measures that would allow for precise decomposition of search times into guidance and decision-making processes. A preliminary treatment of these data was presented by Walenchok, Hout, and Goldinger (2013). The following results expand upon these initial analyses by including more detailed eye-tracking analyses (the number of items fixated and refixated, and decision times) as well as separate analyses for target-present and target-absent trials.

\section{Method}

\section{Participants}

Experiments 3a and 3b included 23 and 23 participants, respectively. All were Arizona State University students who met the same criteria used for Experiments 1and 2. Before beginning the experiment, all participants were screened to ensure that their eyes could be reliably tracked.

\section{Stimuli and design}

The materials and design were identical to Experiment 1 . Participants were shown image target cues in Experiment 3a, and verbal cues in Experiment $3 b$.

\section{Apparatus}

Data were collected on a Dell Optiplex 755 dual-core PC at 2.66 and $1.97 \mathrm{GHz}$, with $3.25 \mathrm{~GB}$ RAM, running Windows XP. Stimuli were presented at $1280 \times 1024$ resolution on a NEC MultiSync 2111 SB CRT monitor (20-in. viewable) at a $75 \mathrm{~Hz}$ refresh rate. The display was controlled by an ATI Radeon HD 2400 XT video card. Eye movements were recorded using an Eyelink 1000 desktop mount system (SR Research Ltd., Mississauga, Ontario, Canada). Temporal resolution was $500 \mathrm{~Hz}$, and spatial resolution was $0.01^{\circ}$. An algorithm used by the Eyelink system automatically partitions ocular motion into saccades, fixations, and blinks; a saccade is defined when eye velocity exceeds $30 \%$ s and acceleration exceeds $8,000 \% \mathrm{~s}^{2}$. The left eye was recorded, but viewing was binocular, and head movements were limited using a chin rest. All stimuli were presented with E-Prime 1.2 software (Schneider et al., 2002) and all eye-tracking data were formatted using Data Viewer software from SR Research.

\section{Procedure}

The procedure was identical to Experiment 1, including the stimulus familiarization task, with the addition of eye-tracking 
procedures: Each participant underwent a 9-point calibration to ensure camera accuracy at the beginning of the experiment, and again at the midpoint of the experiment (after the 2-minute break). The maximum acceptable average calibration error (for all nine points) was $<1.0^{\circ}$, and the maximum error for any single point was $<1.5^{\circ}$. Drift corrections were conducted as needed, if the tracking accuracy decreased.

\section{Results}

Three participants' data were excluded from analysis in Experiment $3 \mathrm{a}-$ one due to poor eye-tracking precision, one due to slow RTs ( $>2.5 S D \mathrm{~s})$, and one due to missing data. Average accuracy for the remaining 20 participants in Experiment 3 a was $94 \%$. Four participants were excluded from analysis in Experiment 3b - one due to poor eye tracking precision and three due to missing data; average accuracy for the remaining 19 participants was $91 \%$. In addition to search RTs, several eye-movement measures were analyzed, including measures derived from fixation frequency, fixation duration, and finally, perceptual decision-making duration. These included (1) a count of distinct distractors fixated per trial (prior to fixating the target, in target-present trials); (2) a count of distractor refixations per trial, before target fixation; (3) the mean duration of distractor fixations per trial, before target fixation; (4) the summed duration of distractor fixations per trial, before target fixation; and (5) decision times in target-present trials. The decision time measure denotes the delay between a participant first fixating a target and subsequently pressing the spacebar. A "fixation" was defined as a participant's gaze landing within the border of an invisible area of interest (AOI) immediately surrounding a given object in the display; the end of this fixation was defined as the participant's gaze exiting the AOI. Small, corrective saccades within an AOI were treated as part of single-object fixations. Eye-movement analyses were conducted separately for target-present and target-absent trials. ${ }^{1}$

\footnotetext{
${ }^{1}$ Data filtering algorithms employed by the Data Viewer software required exclusion of a certain proportion of trials. Specifically, because of the minor spatial eye-tracking error inherent in such experiments, all fixations that fell outside the AOI of any object were placed within the AOI of the object nearest to fixation. However, because the first fixation of each trial began in the center of the display (outside of any object's AOI), this fixation was also placed within the nearest object's AOI. Therefore, we excluded from analysis any target-present trial in which the target was the first item fixated, because one cannot definitively attribute such fixations to participants or the algorithm (i.e., decision-time analyses could have reflected these "false fixations"). Target-present trials in which the target was not fixated were also excluded from all analyses. In target-present trials, $10 \%$ of trials were excluded from in Experiment 3 a because of data filtering, for a total of $20 \%$ of target-present trials excluded (including incorrect trials). Three percent of target-absent trials were excluded from analyses in Experiment 3a because of incorrect responses. In Experiment 3b, 9 \% of target-present trials were excluded due to eye data filtering, for a total of $21 \%$ of target-present trials excluded (including incorrect trials). Six percent of target-absent trials were excluded from Experiment $3 \mathrm{~b}$ due to incorrect responses.
}

Search RTs, Experiment $3 a$

Correct search RTs for Experiment 3a are shown in the upper panels of Fig. 6, with target-absent trials on the left and targetpresent trials on the right. It is readily evident that competition effects were comparable to those in Experiment 1. In the full ANOVA, there were reliable main effects of Load, Target Presence, and Set Size, but the main effect of Competition was marginal. However, the Load $\times$ Competition interaction was significant (see Appendix A, Table A5). In the low-load condition, mean RTs to control and competition trials were equivalent (1,812 $\mathrm{ms}$ and $1,765 \mathrm{~ms}$, respectively), $t(19)=$ $1.16, p=.261$. In the high-load condition, these values reversed and reliably differed, with mean RTs of 3,516 ms and $3,730 \mathrm{~ms}$, respectively), $t(19)=3.19, p=.005, d=.71$. In target-present trials, there were significant main effects of Load and Set Size, and a main effect of Competition, with mean RTs of $1,811 \mathrm{~ms}$ and $1,931 \mathrm{~ms}$ in control and competition trials, respectively. The Load $\times$ Competition interaction was not significant. In the target-absent trials, there were main

\section{Experiment 3a: Image Target Cues}

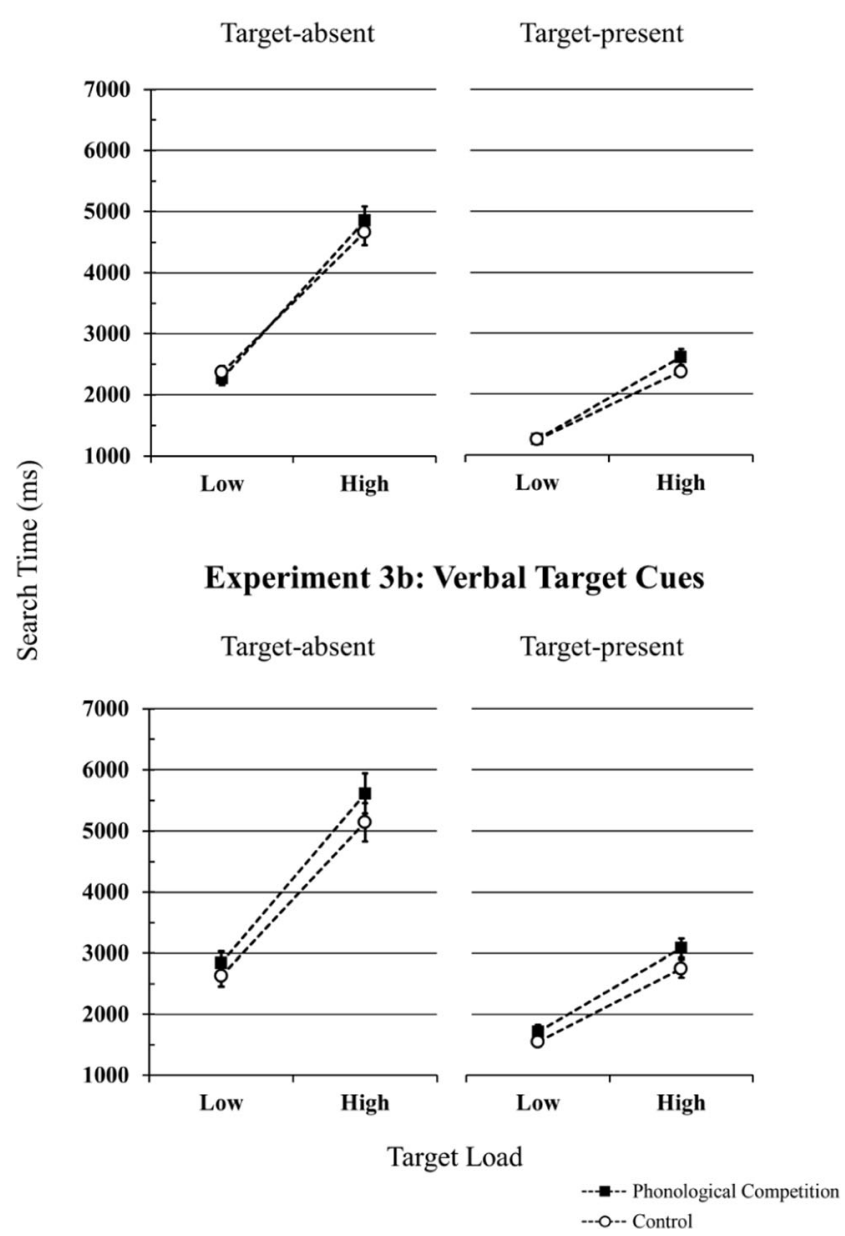

Fig. 6 Search time (RT) as a function of Competition, Load, and Target Presence, in Experiments $3 \mathrm{a}$ and $3 \mathrm{~b}$. Error bars represent \pm 1 SEM 
effects of Load and Set Size, but the main effect of Competition was null. There was, however, a Load $\times$ Competition interaction: Mean RTs to control and competition trials in the low-load condition were opposite to the predicted direction, 2,368 $\mathrm{ms}$ and 2,270 ms, respectively, although this difference was marginal, $t(19)=1.91, p=.071, d=.43$. In the high-load condition, RTs to control and competition trials were in the predicted direction; $4,665 \mathrm{~ms}$ and $4,856 \mathrm{~ms}$, respectively, and this difference was reliable, $t(19)=2.24, p=$ $.037, d=.50$.

\section{Search RTs, Experiment $3 b$}

Correct search RTs for Experiment $3 \mathrm{~b}$ are shown in the lower panels of Fig. 6, again with target-absent trials on the left and target-present trials on the right. In the full ANOVA, there were reliable main effects of Load, Competition, Target Presence, and Set Size. There were several reliable interactions (see Appendix A, Table A6), but the Load $\times$ Competition interaction was marginal. As shown in the lower panels of Fig. 6, the overall RTs in control and competition trials were $3,017 \mathrm{~ms}$ and $3,313 \mathrm{~ms}$, respectively. In target-present trials, there were main effects of Load, Competition, and Set Size, although the Load $\times$ Competition interaction was not reliable. Again, competition effects were equivalent across low and high target load, with RTs of 2,149 ms and 2,399 ms in control and competition trials, respectively. In the target-absent trials, there were again main effects of Load, Competition, and Set Size. The Load $\times$ Competition interaction was not reliable, again demonstrating equivalent competition effects under low and high target load $(3,886 \mathrm{~ms}$ and $4,227 \mathrm{~ms}$ in control and competition trials, respectively).

Overall, the behavioral results from Experiment 3 suggest stronger competition effects in Experiment $3 \mathrm{~b}$ relative to $3 \mathrm{a}$. This was tested with a combined ANOVA testing the Experiment $\times$ Load $\times$ Competition interaction, which was not significant, $F(1,37)=0.17, p=.686$, although the Experiment $\times$ Competition interaction was significant, $F(1$, 37) $=6.54, p=.015, \eta_{\mathrm{p}}^{2}=.15$.

\section{Eye-movement results}

Taken together, the search RTs replicated the previously observed phonological competition effect, although only as a main effect, rather than an interaction (with Load) in Experiment $3 b$. Having replicated the effect, our principal goal was to understand its basis by examining eye-movements. Our approach was fairly exhaustive, as we sought to understand what aspect of eye-movements best explained the competition effect. As might be imagined, nearly every eyemovement measure replicated the major effects observed in search RTs, such as Load and Set Size. When participants take longer to terminate search, they naturally make more fixations. In the interest of brevity, we describe all measures that we investigated, but only show figures and report statistical analyses (Appendix A) for those measures that showed meaningful competition effects.

\section{Number of fixated distractors}

We first examined the number of distractors that were fixated per trial before either finding a target or terminating search. Recall that one hypothesis states that phonological competition may affect attentional guidance, such that participants might examine more irrelevant distractors when they all have similar names. If this were correct, we would expect competition to increase distractor fixations.

Experiment 3a, image cues: In the target-present trials of Experiment 3a, we observed main effects of Load and Set Size, but no effect of Competition or Load $\times$ Competition interaction. In the target-absent trials, we observed main effects of Load and Set Size and a Load $\times$ Set Size interaction, but again, no Competition effect or Load $\times$ Competition interaction.

Experiment 3b, verbal cues: In the target-present trials of Experiment 3b, there were again main effects of Load and Set Size, but no main effect of Competition or Load $\times$ Competition interaction. There was a Load $\times$ Competition $\times$ Set Size interaction, $F(2,17)=7.17, p=$ $.006, \eta_{\mathrm{p}}^{2}=.46$; however, any difference in the number of fixated distractors was very small: Under low target load, the maximum difference between competition and control trials at any given set size was .79 distractor fixations. Under high target load, this maximum difference was 1.36 fixations. In the target-absent trials, we observed main effects of Load and Set Size and a Load $\times$ Set Size interaction, but no Competition effect or any interaction involving Competition. Taking Experiments $3 \mathrm{a}$ and $3 \mathrm{~b}$ together, there was little evidence that phonological competition had any appreciable effect on the number of fixated distractors.

\section{Distractor refixations per trial}

We next examined the number of times that distractors were fixated and then revisited per trial (prior to finding a target in target-present trials), again guided by the hypothesis that phonological competition may affect attentional guidance. If this hypothesis were correct, we might expect to find more refixations in trials with competition, relative to control conditions.

Experiment 3a, image cues: In the target-present trials of Experiment $3 \mathrm{a}$, there was an effect of Load and a marginal effect of Competition, $F(1,19)=3.54, p=.075, \eta_{\mathrm{p}}^{2}=.16$, but 
no Load $\times$ Competition interaction. In the target-absent trials, we observed main effects of Load and Set Size, but no main effect of Competition. We did, however, observe a Load $\times$ Set Size and a Load $\times$ Competition interaction, $F(1,19)=5.73, p$ $=.027, \eta_{\mathrm{p}}^{2}=.23$, although any difference in the mean count of distractor refixations was very small: Under low load, there were 1.54 and 1.29 refixations in control and competition conditions, respectively, $t(19)=2.61, p=.017, d=.58$. Under high load, there were 5.67 and 5.84 refixations in the control and competition conditions, respectively, and this difference was not significant, $t(19)=0.97, p=.344$.

Experiment 3b, verbal cues: In the target-present trials of Experiment $3 \mathrm{~b}$, there were main effects of Load and Competition, $F(1,18)=19.42, p<.001, \eta_{\mathrm{p}}^{2}=.52$, and a Load $\times$ Competition interaction, $F(1,18)=9.77, p=.006$, $\eta_{\mathrm{p}}^{2}=.35$. Again, however, the effect was very small: Under low load, there were .42 and .56 refixations in control and competition conditions, respectively, $t(18)=1.62, p=.123$. Under high load, there were 1.62 and 2.44 refixations, respectively, $t(18)=4.07, p=.001, d=.93$. In the target-absent trials of Experiment 3b, there were main effects of Load, Set Size, and Competition, $F(1,18)=4.65, p=.045, \eta_{\mathrm{p}}^{2}=.21$. There was also a Load $\times$ Set Size interaction and a marginal Competition $\times$ Set Size interaction, $F(2,17)=2.81, p=$ $.088, \eta_{\mathrm{p}}^{2}=.25$. Despite the main effect of Competition, however, the difference between control and competition trials was again negligible, with 4.48 and 4.98 refixations, respectively. Considering Experiments $3 \mathrm{a}$ and $3 \mathrm{~b}$ together, there were no indications that phonological competition appreciably affected the likelihood of revisiting previously fixated distractors.

\section{Mean distractor fixation durations}

Having found little evidence that phonological competition affects attentional guidance, we next focused on distractor rejection, beginning with mean fixation time per distractor. In this case, the hypothesis is that phonological similarity evokes weak resonance between the potential targets (held in WM) and fixated distractors, causing observers to consider each distractor slightly longer than they otherwise would. The results for mean distractor fixation durations are shown in Fig. 7, with the same layout as previous figures showing RT results; ANOVA results are shown in Appendix A (Table A7). It is important to note that this measure reflects only first fixation durations, excluding refixations. Additionally, in target-present trials, this measure only includes distractors fixated pre-target, with the remaining trial duration being classified as decision time, which is discussed below. Consequently, there were fewer data points to potentially produce reliable competition effects in target-present trials, relative to targetabsent trials.
Experiment 3a: Image Target Cues

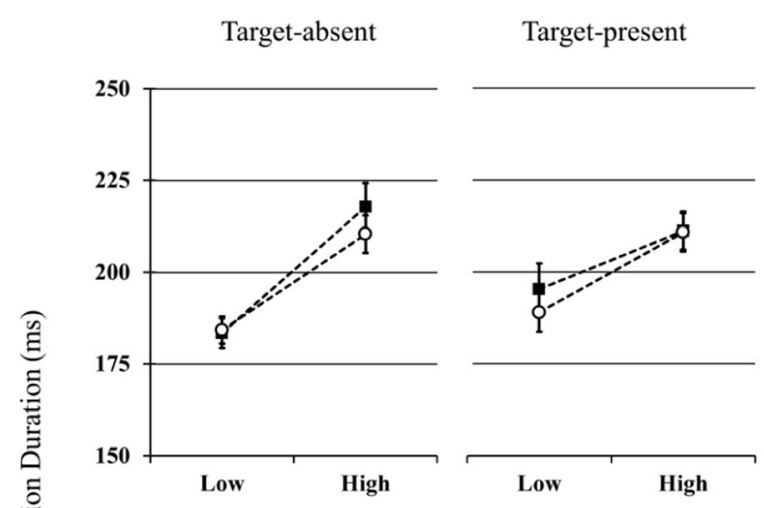

Experiment 3b: Verbal Target Cues

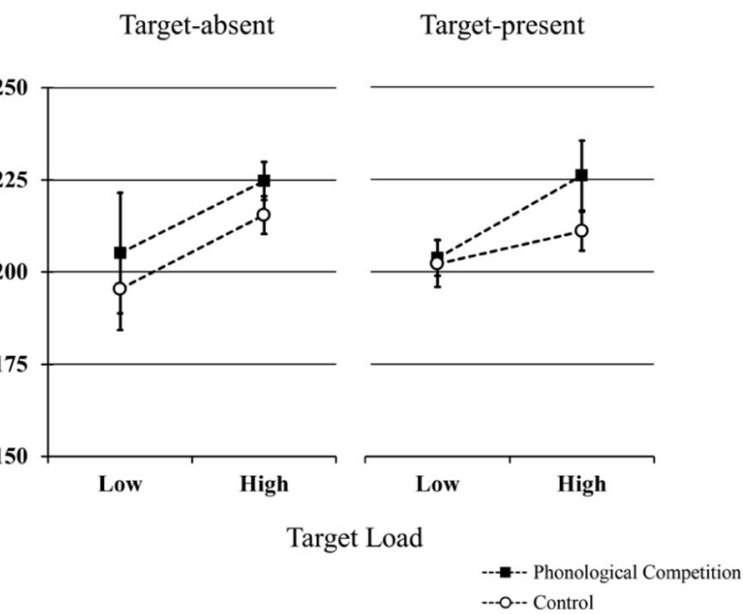

Fig. 7 Mean distractor fixation duration per trial (pre-target in targetpresent trials) as a function of Competition, Load, and Target Presence in Experiments 3a and 3b. Error bars represent \pm 1 SEM

Experiment 3a, image cues: In the target-present trials of Experiment 3a, there was a main effect of Load, but there were no other reliable main effects. The Load $\times$ Competition interaction was not significant, but the Load $\times$ Competition $\times$ Set Size interaction was reliable. In the target-absent trials, there were main effects of Load and Competition, but not Set Size. There was a reliable Load $\times$ Competition interaction, and no other interactions were reliable. As shown in the upper left panel of Fig. 7, in low-load trials, mean distractor fixation durations were equivalent in control and competition conditions (184 $\mathrm{ms}$ and $183 \mathrm{~ms}$, respectively), $t(19)=0.54, p=$ .597. In high-load trials, however, distractor fixations times were slightly longer in competition trials, relative to control trials (218 $\mathrm{ms}$ and $210 \mathrm{~ms}$, respectively), $t(19)=2.53, p=$ $.020, d=.57$.

Experiment 3b, verbal cues: In target-present trials of Experiment 3b, there was a reliable main effect of Load and a marginal effect of Competition, but the Load $\times$ 
Competition interaction was not significant. In the targetabsent trials, there was a marginal main effect of Load and a marginal Load $\times$ Set Size interaction, but the Load $\times$ Competition interaction was again not significant. However, we did observe a reliable Competition effect: As shown in the lower-left panel of Fig. 7, distractor fixations were longer in trials with phonological competition, relative to control trials ( $215 \mathrm{~ms}$ and $205 \mathrm{~ms}$, respectively). Thus, in Experiments $3 \mathrm{a}$ and $3 \mathrm{~b}$, we found that people examined distractors slightly longer when phonological overlap existed between targets and distractors.

\section{Summed distractor fixation durations}

Given the observation that individual distractors were fixated longer in competition trials, relative to control trials, we next verified that summed distractor fixations contributed to the competition effects found in overall search RTs. As with the mean fixation duration measure, these summed durations reflect only first fixations to distractors (excluding refixations) and only distractors fixated pre-target in target-present trials.

Because the results were straightforward, we report only the key effects of interest. In Experiment 3a, there were no main effects of Competition, but we found a marginal Load $\times$ Competition interaction in target-present trials, $F(1,19)=3.25, p=.087, \eta_{\mathrm{p}}^{2}=.15$, and the interaction was significant in target-absent trials $F(1,19)=8.01, p=$ $.011, \eta_{\mathrm{p}}^{2}=.30:$ In target-absent trials, under low load, these durations in control and competition trials did not reliably differ (1,540 $\mathrm{ms}$ and $1,516 \mathrm{~ms}$, respectively), $t(19)=0.80, p=.435$. Under high load, the difference was marginal (2,482 $\mathrm{ms}$ and $2,562 \mathrm{~ms}$, respectively), $t(19)$ $=2.06, p=.054, d=.46$.

In Experiment 3b, there was no effect of Competition in target-present trials, but there was a marginal Load $\times$ Competition interaction, $F(1,18)=3.22, p=.090, \eta_{\mathrm{p}}^{2}=$ .16. In target-absent trials, there was no Load $x$ Competition interaction, but there was a main effect of Competition, $F(1,18)=11.76, p=.003, \eta_{\mathrm{p}}^{2}=.40$, with longer summed fixation durations in the competition $(2,260 \mathrm{~ms})$ compared to the control condition $(2,131 \mathrm{~ms})$. In all cases, the summed fixation duration results closely mirrored search RTs, with weak competition effects with image target cues in Experiment $3 \mathrm{a}$ and stronger effects with verbal cues in Experiment $3 \mathrm{~b}$.

\section{Decision times}

The final eye-tracking measure we examined was decision times in target-present trials, operationally defined as the period between the initial fixation of a target object and the space bar press. The results are shown in Fig. 8, with Experiment $3 \mathrm{a}$ in the left panel and Experiment $3 \mathrm{~b}$ in the

\section{Experiment 3: Decision Times}

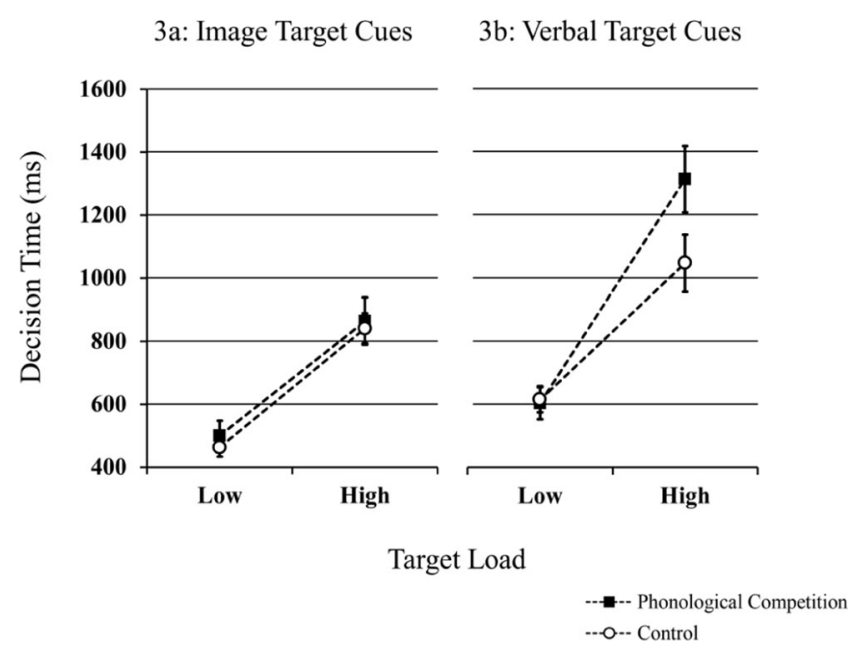

Fig. 8 Decision times (time to press) in target-present trials, as a function of Competition and Load in Experiments 3a and 3b. Error bars represent \pm 1 SEM

right panel. In Experiment 3a, only the main effect of Load was reliable, $F(1,19)=79.74, p<.001, \eta_{\mathrm{p}}^{2}=.81$. Despite a slight numerical trend toward a Competition effect, it was not reliable, $F(1,19)=0.79, p=.387$, nor was the Load $\times$ Competition interaction, $F(1,19)=0.26$, $p=.873$. In Experiment $3 \mathrm{~b}$, there were main effects of Load, $F(1,18)=59.78, p<.001, \eta_{\mathrm{p}}^{2}=.77$, and Competition, $F(1,18)=4.84, p=.041, \eta_{\mathrm{p}}^{2}=.21$. There was a marginal Load $\times$ Set Size interaction, $F(2,17)=$ $3.33, p=.060, \eta_{\mathrm{p}}^{2}=.28$, and the Load $\times$ Competition interaction was reliable, $F(1,18)=10.00, p=.005, \eta_{\mathrm{p}}^{2}$ $=.36$. Under low target load, decision times were equivalent in control and competition trials $(614 \mathrm{~ms}$ and $604 \mathrm{~ms}$, respectively), $t(18)=.222, p=.827$. Under high load, these values diverged, with faster decision times in control trials, relative to competition trials $(1,046 \mathrm{~ms}$ and $1312 \mathrm{~ms}$, respectively), $t(18)=2.88, p=.010, d=.66$. The decision time results suggest that participants were slower to appreciate target objects when targets and distractors had similar names, especially when targets were specified verbally and target load was high.

\section{Discussion}

Experiment 3 was conducted to replicate and extend Experiment 1, with added eye-movement data. As in Experiment 1, search RTs revealed phonological competition effects, particularly when targets were specified via verbal cues. To better understand the phonological competition effect, we examined eye-movement behavior including (1) counts of fixated distractors (2) distractor refixations, (3) average distractor fixation durations, (4) total distractor fixation 
durations, and (5) decision times in target-present trials. These analyses revealed negligible differences in the measures related to attentional guidance: Patterns of fixating and revisiting distractor objects were nearly identical in competition and control trials.

Although phonological competition did not appreciably change how often people considered (or reconsidered) objects, it clearly changed the time-course of distractor rejection and target detection. In the competition condition, people examined each distractor a little longer, relative to control conditions, leading to large cumulative differences. For example, Table 2 shows eye-tracking measures from Experiment 3b, wherein targets were specified verbally. As shown, people generally looked at the same number of objects, regardless of competition. However, they dwelled slightly longer on distractor objects when competition was present. (Although separate control conditions were averaged for all analyses, this pattern held true in the control condition wherein the same distractor objects were viewed in the context of noncompetitor targets.) In the high-load condition, in target-absent trials, competition increased average fixation durations by $10 \mathrm{~ms}(225 \mathrm{~ms}$ vs. $215 \mathrm{~ms}$ ). When we multiply the count of fixated distractors by the mean gaze duration, we find that the cumulative effect is a $131 \mathrm{~ms}$ difference between conditions, which explains about $30 \%$ of the competition effect in search times. People also took longer to make "target-present" decisions when competition was present, especially under high load (Table 2).

These findings comport with those of Meyer et al. (2007), who also found that people take longer to disengage attention from competitors, relative to unrelated distractors. The difference in gaze durations to control and critical items in Meyer et al. (2007) was $14 \mathrm{~ms}$ (138 $\mathrm{ms}$ and $152 \mathrm{~ms}$, respectively), comparable to the $\sim 10$ - $\mathrm{ms}$ interference effect that we observed in Experiment 3. However, unlike the previous findings of Meyer et al. (2007; also Görges et al., 2013), we found no differences in search guidance attributable to phonological competition. As previously mentioned, one possible reason for this discrepancy is task differences: Meyer et al. (2007) and Görges, et al. (2013) presented simple displays with four items in fixed locations. This consistent spatial arrangement potentially enabled participants to covertly attend to objects and retrieve their names prior to fixation, leading to errors in guidance-that is, more first fixations to distractors sharing verbal similarity with the target. In contrast, objects in our displays were widely (and randomly) distributed by comparison. The unpredictable and wide distribution of our displays, combined with the speeded nature of the task, likely prevented activation of distractor names via covert attention and resulting interference in guidance. Furthermore, the fixation and refixation counts that we used to estimate guidance differed from the first fixation probabilities used in previous studies. The first fixation measure was an appropriate index of search guidance in prior studies, which presented competitors and control items in the same displays. This measure would have been inappropriate for our displays, which presented either all competitors or all control objects. In Experiment 3, global measures of guidance (total fixations and refixations) were more fitting, as they reflected overall attentional guidance in the presence of competitor versus non-competitor objects. Clearly, these measures showed no appreciable changes in global guidance due to phonological interference. In contrast, fixation times showed

Table 2 Eye movement results in Experiment 3b (verbal target cues)

\begin{tabular}{|c|c|c|c|c|c|}
\hline & $\begin{array}{l}\text { A. Distractors } \\
\text { fixated }\end{array}$ & $\begin{array}{l}\text { B. Mean distractor } \\
\text { fixation duration }(\mathrm{ms})\end{array}$ & $\mathrm{A} * \mathrm{~B}(\mathrm{~ms})$ & $\begin{array}{l}\text { Decision time } \\
(\mathrm{ms})\end{array}$ & $\begin{array}{l}\text { Search time } \\
(\mathrm{ms})\end{array}$ \\
\hline \multicolumn{6}{|l|}{ Target-absent trials } \\
\hline Competition: Low load & 9.16 & 205 & 1,878 & - & 2,838 \\
\hline Competition: High load & 12.23 & 225 & 2,752 & - & 5,615 \\
\hline Control: Low load & 8.86 & 195 & 1,728 & - & 2,625 \\
\hline Control: High load & 12.19 & 215 & 2,621 & - & 5,147 \\
\hline \multicolumn{6}{|l|}{ Target-present trials } \\
\hline Competition: Low load & 4.23 & 204 & 863 & 604 & 1,717 \\
\hline Competition: High load & 6.66 & 226 & 1,505 & 1,312 & 3,081 \\
\hline Control: Low load & 3.81 & 202 & 770 & 614 & 1,549 \\
\hline Control: High load & 6.47 & 211 & 1,365 & 1,046 & 2,749 \\
\hline
\end{tabular}

Note. A * B is roughly equivalent to the summed initial distractor fixations, per trial, for target-absent trials. In target-present trials, these multiplied values are less representative of the summed initial distractor fixation durations due to the error inherent in having fewer data points (i.e., only considering distractors fixated before the target) 
consistent increases for phonologically-similar versus control distractors, showing that subtle delays in distractor rejection were likely the source of the phonological competition effect.

In summary, the eye-tracking results in Experiment 3 showed that phonological competition generally slows down object processing, rather than changing search patterns. When competition is present, there are increases in distractor rejection times and in target appreciation times, leading to a substantial cumulative effect in search RTs. Both effects indicate that perceptual decisions are impaired when target and distractor names are similar and salient.

\section{General discussion}

In three experiments, we investigated the impact of phonological representations in an ostensibly visual task. A well-known finding in visual search is that background items impair search when they resemble search targets (Duncan \& Humphreys, 1989; Treisman \& Gelade, 1980; Wolfe, et al., 1989). Our goal was to determine whether similar interference occurs when distractors' names share phonological overlap with search targets. The answer was yes, but only when the task was challenging. When looking for singular targets, people were relatively unaffected by phonological competition, but the effect emerged when three potential targets were simultaneously considered. Also, when people were provided with visual target templates, they were relatively unaffected by phonological competition, but the effect increased when targets were specified using verbal labels. A similar pattern was found in the decision-making process of distractor rejection (Experiment 2). Eye-movement analyses (Experiment 3) showed that phonological interference slowed perceptual decisions for both targets and distractors.

As noted earlier, our results suggest two theoretical points. First, as specified in many theories (e.g., Duncan \& Humphreys, 1989; Wolfe, 2007), visual search involves "resonance-seeking" between targets held in WM and objects in the environment (see also Hout, Walenchok, Goldinger, \& Wolfe, 2015). When a person has a search target in mind, attention is drawn toward objects that resemble the target, and perceptual processes evaluate those objects as potential matches. Second, object images are high-dimensional stimuli: Although visual features are clearly primary, objects also have "hidden" dimensions, such as names and various semantic features. This study suggests that when simple visual matching is precluded, object names play a role in perceptual evaluation. This was especially true when search processes were challenged by requiring people to search for multiple potential targets simultaneously.
Why does phonological competition increase during multiple-target search? We suggest several potential accounts, none of which are mutually exclusive. The first relates to processing time: Multiple-target search is cognitively demanding, relative to single-target search. With each distractor fixated, one must compare this distractor to several targets held in memory. It is easy to conceive of object perception as a cascaded process (McClelland, 1979), wherein visual features are available first, followed by activation of names and other information. By such a view, object names would become more prominent as a natural side-effect of longer fixations in multiple-target search. This account nicely accords with the present finding that object names had little effect on visual guidance, but selectively affected item processing times (although, as mentioned, prior studies have shown that covert activation of object names can affect guidance; Görges et al., 2013; Meyer et al., 2007).

A second, related hypothesis is that people struggle to ignore irrelevant information when WM is taxed. For example, Hout and Goldinger $(2010,2012)$ found that observers are more likely to incidentally learn distractor objects when searching for multiple targets. Their findings suggest that, under WM load, people are less able to block out distracting information, such as object names in the present study. Increased memory load can be conceptualized as attention directed inward (Cowan, 2005; Kiyonaga \& Egner, 2013; Oberauer, 2009), reducing capacity to direct attention outward. For example, Conway, Cowan, and Bunting (2001) found increased susceptibility to the cocktail party effect (Moray, 1959) for participants with low WM spans (Daneman \& Carpenter, 1980) relative to high-span participants. In our experiments, rather than classify individuals according to span, we selectively reduced WM capacity by imposing loads.

In this study, we also found that specifying targets via verbal labels increased distractor processing. The minimal phonological interference we observed with visual cues suggests that people are able to maintain detailed target templates in memory during search (Luck \& Vogel, 1997; Vogel, Woodman, \& Luck, 2001). More important, they can likely reject distractors using superficial visual analysis. However, when targets are verbally specified, every distractor object requires more careful analysis - an object cannot be rejected until it has been identified. When all target and distractor names share a common onset, it creates repeated opportunities for distractors to communicate false-positive signals to the perceptual system. Indeed, Huettig and McQueen (2007) found that various object attributes (e.g., visual, semantic, phonological) can become more or less activated depending on task characteristics. Using the visual world paradigm, they instructed participants to freely view displays containing four objects while listening to spoken sentences. Critically, the sentences contained a specific target word that either shared visual, semantic, or phonological information with three of the 
objects in the display. In one experiment, they found that the probability of fixating each type of competitor was cascaded, with fixations to phonological competitors occurring before fixations to shape and semantic competitors. Although the present experiments did not involve spoken targets, using verbal target cues increased the salience of distractor names, creating interference. One possible mechanism for this interference is that verbal cues may require people to rehearse the target names, particularly when there are multiple potential targets. The resulting inner speech may have functioned like the spoken targets in Huettig and McQueen (2007), resulting in competition when the names of "spoken" targets and competing objects overlapped (see also Görges et al., 2013).

The phonological interference observed in this study is reminiscent of cohort competition that can occur during speech perception (Grosjean, 1980; Tyler, 1984). Spoken word perception often requires listeners to resolve ambiguity because many words share similar phonetic onsets. Competition among words particularly arises when early word segments are shared by many potential candidate words in the lexicon (the "cohort"). For instance, when hearing the word beaker, correct selection is unlikely during early perception of the utterance because there are numerous lexical candidates that also contain an initial /bi/ phoneme (e.g., bean, beast, beanie). According to prominent models of speech perception (e.g., COHORT; Marslen-Wilson, 1987, Marslen-Wilson \& Welsh, 1978; TRACE; McClelland \& Elman, 1986), the unfolding speech signal is disambiguated in time as the candidate pool progressively shrinks, until the correct word is determined - at the moment the $/ \mathrm{k} /$ in beaker is perceived, the pool shrinks to fewer words (e.g., become, beak, beaker) until beaker is finally selected (in conjunction with syntactic, contextual, and other constraints).

Supporting this cohort-like account within the visual domain, Allopenna et al. (1998) found that fixations simulated using one such model (TRACE; McClelland \& Elman, 1986) closely matched data from their visual world paradigm experiment: Both participant and simulated fixations to cohort competitor objects increased as phonemes of spoken target and competitor names overlapped in time, with decreasing competitor fixations as the ongoing speech signal narrowed the pool of potential targets. In the present experiments, similar interference was evident in the process of perceptual evaluation, rather than guidance: Cohort overlap elicited longer fixations before attentional disengagement and the eyes moving off to consider another object on-screen. We suggest that, because the object names were all cohort competitors for the target-object names (in this case, all starting with $/ \mathrm{bi} /$ ), it created momentary resonances, subtle hesitations $(\sim 10 \mathrm{~ms})$ per object that accumulated within trials, as name overlap incrementally increased the viability of every distractor object as a potential target.
In conclusion, our findings show that when people search for a single object, they are relatively immune to potential phonological competition from distractors. When looking for multiple simultaneous objects, however, the names of background objects have greater capacity to interfere with search, especially when targets are specified verbally. This interference does not reflect diminished search guidance, but a reduced ability to reject and disengage attention from background distractors. Taken together, the results suggest that when people look for things, they engage in implicit naming as they inspect various objects. Such name activation is likely useful in the vast majority of situations, but can cause interference when too many potential targets "sound like" the intended target.

Acknowledgments This work was supported by NIH Grant R01 HD075800-02 to SDG. We thank Jeffrey Beirow, Kayla Block, Feng Min Chen, Raul Garcia, James Harkins, Ga Young Kim, Jorin Larsen, Jenalee Remy, and Gia Veloria for assistance in data collection. We also thank Tamaryn Menneer and one anonymous reviewer for their helpful comments.

\section{Appendix A: ANOVA results for all experiments}

Table A1 Reliable ANOVA results for RT data, Experiment 1a. Any nonreported effects were not significant

\begin{tabular}{|c|c|c|c|c|c|}
\hline Analysis & Effect & $d f$ & $F$ & $p$ & $\eta_{\mathrm{p}}^{2}$ \\
\hline \multicolumn{6}{|c|}{ Experiment 1a, Overall } \\
\hline & Load (L) & 1,19 & 214.1 & $<.001$ & .92 \\
\hline & Competition (C) & 1,19 & 10.0 & .005 & .34 \\
\hline & Target presence (TP) & 1,19 & 103.2 & $<.001$ & .85 \\
\hline & Set size (SS) & 2,18 & 50.3 & $<.001$ & .85 \\
\hline & $\mathrm{L} \times \mathrm{C}$ & 1,19 & 5.8 & .026 & .24 \\
\hline & $\mathrm{L} \times \mathrm{TP}$ & 1,19 & 54.4 & $<.001$ & .74 \\
\hline & $\mathrm{L} \times \mathrm{SS}$ & 2,18 & 9.6 & .001 & .52 \\
\hline & $\mathrm{TP} \times \mathrm{SS}$ & 2,18 & 21.7 & $<.001$ & .71 \\
\hline & $\mathrm{L} \times \mathrm{TP} \times \mathrm{SS}$ & 2,18 & 3.7 & .044 & .29 \\
\hline \multicolumn{6}{|c|}{ Experiment 1a, Target-Present Trials } \\
\hline & Load (L) & 1,19 & 149.4 & $<.001$ & .89 \\
\hline & Competition (C) & 1,19 & 6.7 & .018 & .26 \\
\hline & Set size (SS) & 2,18 & 12.4 & $<.001$ & .58 \\
\hline & $* \mathrm{~L} \times \mathrm{C}$ & 1,19 & 3.5 & .077 & .16 \\
\hline \multicolumn{6}{|c|}{ Experiment 1a, Target-Absent Trials } \\
\hline & Load (L) & 1,19 & 150.5 & $<.001$ & .89 \\
\hline & Competition (C) & 1,19 & 4.4 & .049 & .19 \\
\hline & Set size (SS) & 2,18 & 46.8 & $<.001$ & .84 \\
\hline & $* \mathrm{~L} \times \mathrm{C}$ & 1,19 & 3.8 & .067 & .17 \\
\hline & $\mathrm{L} \times \mathrm{SS}$ & 2,18 & 10.4 & .001 & .54 \\
\hline
\end{tabular}

Note. * indicates marginal results, included only for key tests of interest 
Table A2 Reliable ANOVA results for RT data, Experiment 1b. Any nonreported effects were not significant

\begin{tabular}{|c|c|c|c|c|c|}
\hline Analysis & Effect & $d f$ & $F$ & $p$ & $\eta_{\mathrm{p}}^{2}$ \\
\hline \multicolumn{6}{|c|}{ Experiment $1 \mathrm{~b}$, Overall } \\
\hline & Load (L) & 1,18 & 210.2 & $<.001$ & .92 \\
\hline & Competition (C) & 1,18 & 19.5 & $<.001$ & .52 \\
\hline & Target presence (TP) & 1,18 & 182.6 & $<.001$ & .91 \\
\hline & Set size (SS) & 2,17 & 51.5 & $<.001$ & .86 \\
\hline & $\mathrm{L} \times \mathrm{C}$ & 1,18 & 12.3 & .003 & .41 \\
\hline & $\mathrm{L} \times \mathrm{TP}$ & 1,18 & 54.6 & $<.001$ & .75 \\
\hline & $\mathrm{C} \times \mathrm{TP}$ & 1,18 & 4.4 & .050 & .20 \\
\hline & $\mathrm{L} \times \mathrm{SS}$ & 2,17 & 13.2 & $<.001$ & .61 \\
\hline & $\mathrm{TP} \times \mathrm{SS}$ & 2,17 & 16.9 & $<.001$ & .67 \\
\hline & $\mathrm{L} \times \mathrm{C} \times \mathrm{TP}$ & 1,18 & 13.8 & .002 & .44 \\
\hline \multicolumn{6}{|c|}{ Experiment $1 \mathrm{~b}$, Target-Present Trials } \\
\hline & Load (L) & 1,18 & 140.9 & $<.001$ & .89 \\
\hline & *Competition $(\mathrm{C})$ & 1,18 & 4.2 & .055 & .19 \\
\hline & Set size (SS) & 2,17 & 14.3 & $<.001$ & .63 \\
\hline & $\dagger \mathrm{L} \times \mathrm{C}$ & 1,18 & 1.7 & .205 & $\mathrm{n} / \mathrm{a}$ \\
\hline & $\mathrm{L} \times \mathrm{SS}$ & 2,17 & 4.9 & .021 & .36 \\
\hline \multicolumn{6}{|c|}{ Experiment $1 \mathrm{~b}$, Target-Absent Trials } \\
\hline & Load (L) & 1,18 & 187.8 & $<.001$ & .91 \\
\hline & Competition (C) & 1,18 & 21.9 & $<.001$ & .55 \\
\hline & Set size (SS) & 2,17 & 57.4 & $<.001$ & .87 \\
\hline & $\mathrm{L} \times \mathrm{C}$ & 1,18 & 35.9 & $<.001$ & .67 \\
\hline & $\mathrm{L} \times \mathrm{SS}$ & 2,17 & 11.5 & .001 & .58 \\
\hline
\end{tabular}

Note. * indicates marginal results, included only for key tests of interest $\dagger$ indicates null results, included only for key tests of interest

Table A3 Reliable ANOVA results for mean distractor rejection times, Experiment 2a. Any nonreported effects were not significant

\begin{tabular}{clllll}
\hline Analysis & Effect & $d f$ & $F$ & $p$ & $\eta_{\mathrm{p}}^{2}$ \\
\hline Experiment 2a, Overall & & & & \\
Load (L) & 1,21 & 161.1 & $<.001$ & .89 \\
Competition (C) & 1,21 & 14.3 & .001 & .40 \\
Target presence (TP) & 1,21 & 7.0 & .015 & .25 \\
L $\times$ C & 1,21 & 8.8 & .007 & .30 \\
L $\times$ TP & 1,21 & 7.2 & .014 & .26
\end{tabular}

Experiment 2a, Target-Present Trials

$\begin{array}{lllll}\text { Load (L) } & 1,21 & 133.4 & <.001 & .86 \\ \text { Competition (C) } & 1,21 & 10.0 & .005 & .32 \\ \mathrm{~L} \times \mathrm{C} & 1,21 & 9.0 & .007 & .30\end{array}$

Experiment 2a, Target-Absent Trials

\begin{tabular}{lllll} 
Load (L) & 1,21 & 170.2 & $<.001$ & .89 \\
Competition (C) & 1,21 & 5.1 & .035 & .20 \\
$* \mathrm{~L} \times \mathrm{C}$ & 1,21 & 3.3 & .082 & .14 \\
\hline
\end{tabular}

Note. * indicates marginal results, included only for key tests of interest
Table A4 Reliable ANOVA results for mean distractor rejection times, Experiment $2 \mathrm{~b}$. Any nonreported effects were not significant

\begin{tabular}{|c|c|c|c|c|c|}
\hline Analysis & Effect & $d f$ & $F$ & $p$ & $\eta_{\mathrm{p}}^{2}$ \\
\hline \multicolumn{6}{|c|}{ Experiment 2b, Overall } \\
\hline & Load (L) & 1,19 & 97.1 & $<.001$ & .84 \\
\hline & Competition (C) & 1,19 & 42.9 & $<.001$ & .69 \\
\hline & $\mathrm{L} \times \mathrm{C}$ & 1,19 & 48.1 & $<.001$ & .72 \\
\hline \multicolumn{6}{|c|}{ Experiment $2 \mathrm{~b}$, Target-Present Trials } \\
\hline & Load (L) & 1,19 & 105.3 & $<.001$ & .85 \\
\hline & Competition (C) & 1,19 & 26.7 & $<.001$ & .59 \\
\hline & $\mathrm{L} \times \mathrm{C}$ & 1,19 & 25.5 & $<.001$ & .57 \\
\hline \multicolumn{6}{|c|}{ Experiment $2 b$, Target-Absent Trials } \\
\hline & Load (L) & 1,19 & 74.4 & $<.001$ & .80 \\
\hline & Competition (C) & 1,19 & 34.7 & $<.001$ & .65 \\
\hline & $\mathrm{L} \times \mathrm{C}$ & 1,19 & 33.5 & $<.001$ & .64 \\
\hline
\end{tabular}

Table A5 Reliable ANOVA results for search RTs, Experiment 3a. Any nonreported effects were not significant

\begin{tabular}{|c|c|c|c|c|c|}
\hline Analysis & Effect & $\mathrm{df}$ & $F$ & $p$ & $\eta_{p}^{2}$ \\
\hline \multicolumn{6}{|c|}{ Experiment $3 \mathrm{a}$, Overall } \\
\hline & Load (L) & 1,19 & 246.1 & $<.001$ & .93 \\
\hline & *Competition $(\mathrm{C})$ & 1,19 & 4.3 & .052 & .19 \\
\hline & Target presence (TP) & 1,19 & 202.6 & $<.001$ & .91 \\
\hline & Set size (SS) & 2,18 & 72.4 & $<.001$ & .89 \\
\hline & $\mathrm{L} \times \mathrm{C}$ & 1,19 & 11.6 & .003 & .38 \\
\hline & $\mathrm{L} \times \mathrm{TP}$ & 1,19 & 99.8 & $<.001$ & .84 \\
\hline & $\mathrm{L} \times \mathrm{SS}$ & 2,18 & 11.3 & .001 & .56 \\
\hline & $\mathrm{TP} \times \mathrm{SS}$ & 2,18 & 29.2 & $<.001$ & .76 \\
\hline & $\mathrm{L} \times \mathrm{TP} \times \mathrm{SS}$ & 2,18 & 5.4 & .015 & .37 \\
\hline \multicolumn{6}{|c|}{ Experiment 3a, Target-Present Trials } \\
\hline & Load (L) & 1,19 & 176.0 & $<.001$ & .90 \\
\hline & Competition (C) & 1,19 & 4.5 & .047 & .19 \\
\hline & Set size (SS) & 2,18 & 8.8 & .002 & .50 \\
\hline & $\dagger \mathrm{L} \times \mathrm{C}$ & 1,19 & 2.8 & .113 & $\mathrm{n} / \mathrm{a}$ \\
\hline \multicolumn{6}{|c|}{ Experiment 3a, Target-Absent Trials } \\
\hline & Load (L) & 1,19 & 227.9 & $<.001$ & .92 \\
\hline & $†$ Competition $(\mathrm{C})$ & 1,19 & 0.6 & .442 & $\mathrm{n} / \mathrm{a}$ \\
\hline & Set size (SS) & 2,18 & 76.0 & $<.001$ & .89 \\
\hline & $\mathrm{L} \times \mathrm{C}$ & 1,19 & 14.4 & .001 & .43 \\
\hline & $\mathrm{L} \times \mathrm{SS}$ & 2,18 & 13.0 & $<.001$ & .59 \\
\hline
\end{tabular}

Note. * indicates marginal results, included only for key tests of interest $\dagger$ indicates null results, included only for key tests of interest 
Table A6 Reliable ANOVA results for search RTs, Experiment 3b. Any nonreported effects were not significant

\begin{tabular}{|c|c|c|c|c|c|}
\hline Analysis & Effect & $d f$ & $F$ & $p$ & $\eta_{p}^{2}$ \\
\hline \multicolumn{6}{|c|}{ Experiment $3 \mathrm{~b}$, Overall } \\
\hline & Load (L) & 1,18 & 279.4 & $<.001$ & .94 \\
\hline & Competition (C) & 1,18 & 16.0 & .001 & .47 \\
\hline & Target presence (TP) & 1,18 & 122.2 & $<.001$ & .87 \\
\hline & Set size (SS) & 2,17 & 58.5 & $<.001$ & .87 \\
\hline & $* \mathrm{~L} \times \mathrm{C}$ & 1,18 & 4.3 & .052 & .19 \\
\hline & $\mathrm{L} \times \mathrm{TP}$ & 1,18 & 79.0 & $<.001$ & .81 \\
\hline & $\mathrm{L} \times \mathrm{SS}$ & 2,17 & 7.6 & .004 & .47 \\
\hline & $\mathrm{TP} \times \mathrm{SS}$ & 2,17 & 10.0 & .001 & .54 \\
\hline & $\mathrm{L} \times \mathrm{TP} \times \mathrm{SS}$ & 2,17 & 4.3 & .030 & .34 \\
\hline \multicolumn{6}{|c|}{ Experiment $3 b$, Target-Present Trials } \\
\hline & Load (L) & 1,18 & 150.8 & $<.001$ & .89 \\
\hline & Competition (C)1, 18 & 8.7 & .009 & .33 & \\
\hline & Set size (SS) & 2,17 & 4.1 & .035 & .33 \\
\hline & $\dagger \mathrm{L} \times \mathrm{C}$ & 1,18 & 2.6 & .127 & $\mathrm{n}$ \\
\hline \multicolumn{6}{|c|}{ Experiment 3b, Target-Absent Trials } \\
\hline & Load (L) & 1,18 & 245.6 & $<.001$ &. \\
\hline & Competition (C) & 1,18 & 12.9 & .002 &. \\
\hline & Set size (SS) & 2,17 & 50.9 & $<.001$ & . \\
\hline & $\dagger \mathrm{L} \times \mathrm{C}$ & 1,18 & 1.9 & .180 & $\mathrm{n}$ \\
\hline & $\mathrm{L} \times \mathrm{SS}$ & 2,17 & 13.7 & $<.001$ & .62 \\
\hline & $\mathrm{C} \times \mathrm{SS}$ & 2,17 & 4.8 & .022 & .36 \\
\hline
\end{tabular}

Note. * indicates marginal results, included only for key tests of interest $\dagger$ indicates null results, included only for key tests of interest
Table A7 Reliable ANOVA results for mean distractor fixation durations, Experiments $3 \mathrm{a}$ and $3 \mathrm{~b}$. Any nonreported effects were not significant

\begin{tabular}{|c|c|c|c|c|c|}
\hline Analysis & Effect & $d f$ & $F$ & $p$ & $\eta_{\mathrm{p}}^{2}$ \\
\hline \multicolumn{6}{|c|}{ Experiment 3a, Target-Present Trials } \\
\hline & Load (L) & 1,19 & 21.5 & $<.001$ & .53 \\
\hline & $\dagger$ Competition (C) & 1,19 & 1.0 & .336 & $\mathrm{n} / \mathrm{a}$ \\
\hline & $\dagger \mathrm{L} \times \mathrm{C}$ & 1,19 & 0.9 & .348 & $\mathrm{n} / \mathrm{a}$ \\
\hline & $\mathrm{L} \times \mathrm{C} \times \mathrm{SS}$ & 2,18 & 3.9 & .039 & .30 \\
\hline \multicolumn{6}{|c|}{ Experiment 3a, Target-Absent Trials } \\
\hline & Load (L) & 1,19 & 65.0 & $<.001$ & .77 \\
\hline & Competition (C) & 1,19 & 4.7 & .043 & .20 \\
\hline & $\mathrm{L} \times \mathrm{C}$ & 1,19 & 5.1 & .036 & .21 \\
\hline \multicolumn{6}{|c|}{ Experiment 3b, Target-Present Trials } \\
\hline & Load (L) & 1,18 & 7.4 & .014 & .29 \\
\hline & *Competition $(\mathrm{C})$ & 1,18 & 3.7 & .071 & .17 \\
\hline & $\dagger \mathrm{L} \times \mathrm{C}$ & 1,18 & 2.5 & .133 & $\mathrm{n} / \mathrm{a}$ \\
\hline \multicolumn{6}{|c|}{ Experiment $3 b$, Target-Absent Trials } \\
\hline & Competition (C) & 1,18 & 11.1 & .004 & .38 \\
\hline & $\dagger \mathrm{L} \times \mathrm{C}$ & 1,18 & $<0.1$ & .933 & $\mathrm{n} / \mathrm{a}$ \\
\hline
\end{tabular}

Note. * indicates marginal results, included only for key tests of interest $\dagger$ indicates null results, included only for key tests of interest 


\section{Appendix B: Means in all control conditions}

Table B1 Mean search RTs in ms (distractor rejection times in Experiment 2) for all control conditions in each experiment. Unless otherwise indicated, the control conditions did not significantly differ or interact with Load (all $p \mathrm{~s}>.050$ )

\begin{tabular}{|c|c|c|c|c|c|c|}
\hline & \multicolumn{2}{|c|}{ Control 1: /bi/ targets, varied distractors } & \multicolumn{2}{|c|}{ Control 2: Varied targets, /bi/ distractors } & \multicolumn{2}{|c|}{ Control 3: Varied targets, varied distractors } \\
\hline & Low load & High load & Low load & High load & Low load & High load \\
\hline \multicolumn{7}{|l|}{ Experiment 1a } \\
\hline Overall & 1,870 & 3,547 & 1,868 & 3,603 & 1,856 & 3,696 \\
\hline Target-present trials & 1,336 & 2,330 & 1,253 & 2,250 & 1,280 & 2,266 \\
\hline Target-absent trials ${ }^{\mathrm{a}, \mathrm{b}}$ & 2,403 & 4,763 & 2,482 & 4,956 & 2,432 & 5,127 \\
\hline \multicolumn{7}{|l|}{ Experiment $1 \mathrm{~b}$} \\
\hline Overall & 2,272 & 4,243 & 2,276 & 4,294 & 2,221 & 4,309 \\
\hline Target-present trials & 1,610 & 3,081 & 1,580 & 3,122 & 1,520 & 3,053 \\
\hline Target-absent trials & 2,934 & 5,406 & 2,972 & 5,465 & 2,922 & 5,565 \\
\hline \multicolumn{7}{|l|}{ Experiment $2 \mathrm{a}$} \\
\hline Overall $^{\mathrm{a}, \mathrm{b}}$ & 414 & 607 & 412 & 559 & 404 & 574 \\
\hline Target-present trials ${ }^{\mathrm{a}, \mathrm{b}}$ & 421 & 625 & 417 & 562 & 406 & 592 \\
\hline Target-absent trials $^{\mathrm{a}}$ & 408 & 590 & 406 & 557 & 402 & 557 \\
\hline \multicolumn{7}{|l|}{ Experiment $2 \mathrm{~b}$} \\
\hline Overall $^{\mathrm{a}}$ & 458 & 738 & 453 & 703 & 447 & 717 \\
\hline Target-present trials ${ }^{\mathrm{a}}$ & 465 & 772 & 461 & 703 & 441 & 733 \\
\hline Target-absent trials & 451 & 704 & 445 & 702 & 453 & 700 \\
\hline \multicolumn{7}{|l|}{ Experiment 3a } \\
\hline Overall & 1,812 & 3,479 & 1,801 & 3,602 & 1,823 & 3,467 \\
\hline Target-present trials & 1,305 & 2,383 & 1,240 & 2,365 & 1,222 & 2,350 \\
\hline Target-absent trials ${ }^{\mathrm{c}}$ & 2,319 & 4,574 & 2,362 & 4,838 & 2,424 & 4,584 \\
\hline \multicolumn{7}{|l|}{ Experiment $3 b$} \\
\hline Overall & 2,129 & 3,966 & 2,030 & 3,876 & 2,101 & 4,002 \\
\hline Target-present trials ${ }^{\mathrm{a}}$ & 1,653 & 2,849 & 1,455 & 2,601 & 1,539 & 2,798 \\
\hline Target-absent trials & 2,605 & 5,083 & 2,606 & 5,151 & 2,663 & 5,207 \\
\hline
\end{tabular}

${ }^{\text {a }}$ Significant main effect of Control Type (all $p s<.050$ )

${ }^{\mathrm{b}}$ Significant Load $\times$ Control Type interaction $($ all $p \mathrm{~s}<.050)$

${ }^{\mathrm{c}}$ Marginal Load $\times$ Control Type interaction $(p=.097)$ 
Table B2 Mean eye-tracking results for all control conditions in Experiment 3. Unless otherwise indicated, the control conditions did not significantly differ or interact with Load (all $p \mathrm{~s}>.050$ )

\begin{tabular}{|c|c|c|c|c|c|c|}
\hline & \multicolumn{2}{|c|}{$\begin{array}{l}\text { Control 1: /bi/ targets, } \\
\text { varied distractors }\end{array}$} & \multicolumn{2}{|c|}{$\begin{array}{l}\text { Control 2: Varied } \\
\text { targets, /bi/ distractors }\end{array}$} & \multicolumn{2}{|c|}{$\begin{array}{l}\text { Control 3: Varied targets, } \\
\text { varied distractors }\end{array}$} \\
\hline & Low load & High load & Low load & High load & Low load & High load \\
\hline \multicolumn{7}{|l|}{ Number of Fixated Distractors } \\
\hline \multicolumn{7}{|l|}{ Experiment 3a } \\
\hline Target-present trials & 3.38 & 5.73 & 3.30 & 5.67 & 3.13 & 5.82 \\
\hline Target-absent trials ${ }^{\mathrm{a}}$ & 8.16 & 11.57 & 8.44 & 11.96 & 8.43 & 11.76 \\
\hline \multicolumn{7}{|l|}{ Experiment $3 b$} \\
\hline Target-present trials ${ }^{\mathrm{b}, \mathrm{c}}$ & 4.17 & 6.50 & 3.60 & 6.22 & 3.65 & 6.71 \\
\hline Target-absent trials & 8.75 & 11.97 & 8.84 & 12.33 & 8.98 & 12.28 \\
\hline \multicolumn{7}{|c|}{ Mean Distractor Fixation Durations (ms) } \\
\hline \multicolumn{7}{|l|}{ Experiment $3 \mathrm{a}$} \\
\hline Target-present trials & 187 & 208 & 187 & 217 & 192 & 208 \\
\hline Target-absent trials & 185 & 210 & 183 & 212 & 184 & 209 \\
\hline \multicolumn{7}{|l|}{ Experiment $3 b$} \\
\hline Target-present trials & 204 & 212 & 203 & 210 & 200 & 211 \\
\hline Target-absent trials & 199 & 213 & 197 & 216 & 189 & 217 \\
\hline \multicolumn{7}{|c|}{ Summed Distractor Fixation Durations (ms) } \\
\hline \multicolumn{7}{|l|}{ Experiment $3 \mathrm{a}$} \\
\hline Target-present trials & 559 & 993 & 567 & 1,006 & 544 & 1,003 \\
\hline Target-absent trials ${ }^{\mathrm{a}, \mathrm{d}}$ & 1,517 & 2,440 & 1,536 & 2,548 & 1,566 & 2,459 \\
\hline \multicolumn{7}{|l|}{ Experiment $3 b$} \\
\hline Target-present trials & 725 & 1,120 & 634 & 1,098 & 617 & 1,171 \\
\hline Target-absent trials & 1,656 & 2,539 & 1,649 & 2,616 & 1,688 & 2,639 \\
\hline \multicolumn{7}{|l|}{ Decision Times (ms) } \\
\hline \multicolumn{7}{|l|}{ Experiment $3 \mathrm{a}$} \\
\hline Target-present trials & 494 & 873 & 445 & 845 & 449 & 804 \\
\hline \multicolumn{7}{|l|}{ Experiment $3 b$} \\
\hline Target-present trials $\mathrm{e}^{\mathrm{e}}$ & 649 & 1172 & 545 & 966 & 649 & 1002 \\
\hline
\end{tabular}

${ }^{\text {a }}$ Significant main effect of Control Type $(p<.050)$

${ }^{\mathrm{b}}$ Marginal main effect of Control Type $(p=.093)$

${ }^{\mathrm{c}}$ Marginal Load $\times$ Control Type interaction $(p=.064)$

${ }^{\mathrm{d}}$ Marginal Load $\times$ Control Type interaction $(p=.082)$

${ }^{\mathrm{e}}$ Marginal main effect of Control Type $(p=.095)$

\section{References}

Allopenna, P. D., Magnuson, J. S., \& Tanenhaus, M. K. (1998). Tracking the time course of spoken word recognition using eye movements: Evidence for continuous mapping models. Journal of Memory and Language, 38, 419-439. doi:10.1006/jmla.1997.2558

Baddeley, A. D., \& Hitch, G. J. (1974). Working memory. In G. Bower (Ed.), The psychology of learning and motivation: Advances in research and theory (Vol. 8, pp. 47-89). New York: Academic Press. doi:10.1016/S0079-7421(08)60452-1
Conway, A. R. A., Cowan, N., \& Bunting, M. F. (2001). The cocktail party phenomenon revisited: The importance of working memory capacity. Psychonomic Bulletin \& Review, 8(2), 331-335. doi:10.3758/BF03196169

Cowan, N. (2005). Working memory capacity. New York: Psychology Press. doi:10.4324/9780203342398

Dahan, D., \& Tanenhaus, M. K. (2005). Looking at the rope when looking for the snake: Conceptually mediated eye movements during spoken-word recognition. Psychonomic Bulletin \& Review, 12(3), 453-459. doi:10.3758 /BF03193787 
Daneman, M., \& Carpenter, P. A. (1980). Individual differences in working memory and reading. Journal of Verbal Learning and Behavior, 19(4), 450-466. doi:10.1016/S0022-5371(80)90312-6

Duncan, J., \& Humphreys, G. W. (1989). Visual search and stimulus similarity. Psychological Review, 96(3), 433-458. doi:10.1037 /0033-295X.96.3.433

Fleck, M. S., \& Mitroff, S. R. (2007). Rare targets are rarely missed in correctable search. Psychological Science, 18(11), 943-977. doi:10.1111/j.1467-9280.2007.02006.x

Godwin, H., Hout, M. C., \& Menneer, T. (2014). Visual similarity is stronger than semantic similarity in guiding visual search for numbers. Psychonomic Bulletin \& Review, 21, 689-695. doi:10.3758 /s13423-013-0547-4

Görges, F., Oppermann, F., Jescheniak, J. D., \& Schriefers, H. (2013). Activation of phonological competitors in visual search. Acta Psychologica, 143, 168-175. doi:10.1016/j.actpsy.2013.03.006

Grosjean, F. (1980). Spoken word recognition processes and the gating paradigm. Perception \& Psychophysics, 28(4), 267-283. doi:10.3758/BF03204386

Hout, M. C., \& Goldinger, S. D. (2010). Learning in repeated visual search. Attention, Perception, \& Psychophysics, 72(5), 1267-1282. doi:10.3758/APP.72.5.1267

Hout, M. C., \& Goldinger, S. D. (2012). Incidental learning speeds visual search by lowering response thresholds, not by improving efficiency: Evidence from eye movements. Journal of Experimental Psychology: Human Perception and Performance, 38, 90-112. doi:10.1037/a0023894

Hout, M. C., \& Goldinger, S. D. (2015). Target templates: The precision of mental representations affects attentional guidance and decisionmaking in visual search. Attention, Perception, \& Psychophysics, 77, 128-149. doi:10.3758/s13414-014-0764-6

Hout, M. C., Walenchok, S. C., Goldinger, S. D., \& Wolfe, J. M. (2015). Failures of perception in the low-prevalence effect: Evidence from active and passive visual search. Journal of Experimental Psychology: Human Perception and Performance, 41, 977-994. doi:10.1037/xhp0000053

Huettig, F., \& Altmann, G. T. M. (2004). The online processing of ambiguous and unambiguous words in context: Evidence from headmounted eye-tracking. In M. Carreiras \& C. Clifton (Eds.), The online study of sentence comprehension: Eyetracking, ERP and beyond (pp. 187-207). New York: Psychology Press.

Huettig, F., \& Altmann, G. T. M. (2005). Word meaning and the control of eye fixation: Semantic competitor effects and the visual world paradigm. Cognition, 96, B23-B32. doi:10.1016/j. cognition.2004.10.003

Huettig, F., \& McQueen, J. M. (2007). The tug of war between phonological, semantic and shape information in language-mediated visual search. Journal of Memory and Language, 57, 460-482. doi:10.1016/j.jml.2007.02.001

Keppel, G., \& Wickens, T. D. (2004). Design and analysis: A researcher's handbook (4th ed.). Upper Saddle River: Prentice Hall.

Kiyonaga, A., \& Egner, T. (2013). Working memory as internal attention: Toward an integrative account of internal and external selection processes. Psychonomic Bulletin \& Review, 20(2), 228-242. doi:10.3758/s13423-012-0359-y

Luck, S. J., \& Vogel, E. K. (1997). The capacity of visual working memory for features and conjunctions. Nature, 390, 279-291. doi: $10.1038 / 36846$

Marslen-Wilson, W. D. (1987). Functional parallelism in spoken wordrecognition. Cognition, 25, 71-102. doi:10.1016/0010-0277(87 )90005-9

Marslen-Wilson, W. D., \& Welsh, A. (1978). Processing interactions and lexical access during word recognition in continuous speech. Cognitive Psychology, 10, 29-63. doi:10.1016/0010-0285(78 )90018-X
McClelland, J. L. (1979). On the time relations of mental processes: An examination of systems of processes in cascade. Psychological Review, 86, 287-330. doi:10.1037/0033-295X.86.4.287

McClelland, J. L., \& Elman, J. L. (1986). The TRACE model of speech perception. Cognitive Psychology, 18, 1-86. doi:10.1016/00100285(86)90015-0

Menneer, T., Stroud, M. J., Cave, K. R., Li, X., Godwin, H. J., Liversedge, S. P., \& Donnelly, N. (2012). Search for two categories of target produces fewer fixations to target-color items. Journal of Experimental Psychology: Applied, 18(4), 404 418. doi:10.1037/a0031032

Meyer, A. S., Belke, E., Telling, A. L., \& Humphreys, G. W. (2007). Early activation of object names in visual search. Psychonomic Bulletin \& Review, 14(4), 710-716. doi:10.3758/BF03196826

Moores, E., Laiti, L., \& Chelazzi, L. (2003). Associative knowledge controls deployment of selective attention. Nature Neuroscience, 6(2), 182-189. doi:10.1038/nn996

Moray, N. (1959). Attention in dichotic listening: Affective cues and the influence of instructions. Quarterly Journal of Experimental Psychology, 11, 56-60. doi:10.1080/17470215908416289

Oberauer, K. (2009). Design for a working memory. Psychology of Learning and Motivation, 51, 45-100. doi:10.1016/S0079-7421 (09)51002-X

Righi, G., Blumstein, S. E., Mertus, J., \& Worden, M. S. (2010). Neural systems underlying lexical competition: An eye tracking and fMRI study. Journal of Cognitive Neuroscience, 22(2), 213-224. doi:10.1162/jocn.2009.21200

Schmidt, J., \& Zelinsky, G. J. (2009). Search guidance is proportional to the categorical specificity of a target cue. The Quarterly Journal of Experimental Psychology, 62(10), 904-1914. doi:10.1080 $/ 17470210902853530$

Schneider, W., Eschman, A., \& Zuccolotto, A. (2002). E-Prime user's guide. Pittsburgh: Psychology Software Tools.

Treisman, A. M., \& Gelade, G. (1980). A feature-integration theory of attention. Cognitive Psychology, 12, 97-136. doi:10.1016/00100285(80)90005-5

Tyler, L. K. (1984). The structure of the initial cohort: Evidence from gating. Perception \& Psychophysics, 36(5), 417-427. doi:10.3758 /BF03207496

Vogel, E. K., Woodman, G. F., \& Luck, S. J. (2001). Storage of features, conjunctions, and objects in visual working memory. Journal of Experimental Psychology: Human Perception and Performance, 27(1), 92-114. doi:10.1037//0096-1523.27.1.92

Walenchok, S. C., Hout, M. C., \& Goldinger, S. D. (2013). What does that picture sound like to you? Oculomotor evidence for phonological competition in visual search. Visual Cognition, 21, 718-722. doi:10.1080/13506285.2013.844970

Wolfe, J. M. (2007). Guided Search 4.0: Current progress with a model of visual search. In W. Gray (Ed.), Integrated models of cognitive systems (pp. 99-119). New York: Oxford University Press. doi:10.1093/acprof:oso/9780195189193.003.0008

Wolfe, J. M., Cave, K. R., \& Franzel, S. L. (1989). Guided Search: An alternative to the feature integration model for visual search. Journal of Experimental Psychology: Human Perception and Performance, 15, 419-433. doi:10.1037/0096-1523.15.3.419

Yee, E., Overton, E., \& Thompson-Schill, S. L. (2009). Looking for meaning: Eye movements are sensitive to overlapping semantic features, not association. Psychonomic Bulletin and Review, 16(5), 869-874. doi:10.3758/PBR.16.5.869

Yee, E., \& Sedivy, J. C. (2006). Eye movements to pictures reveal transient semantic activation during spoken word recognition. Journal of Experimental Psychology: Learning, Memory, and Cognition, 32(1), 1-14. doi:10.1037/0278-7393.32.1.1

Zelinsky, G. J., \& Murphy, G. L. (2000). Synchronizing visual and language processing: An effect of object name length on eye movements. Psychological Science, 11(2), 125-131. doi:10.1111/14679280.00227 